\author{
University of Texas Rio Grande Valley \\ ScholarWorks @UTRGV
}

\title{
Getting on and Moving Up the Property Ladder: Real Hedging in the US Housing Market Before and After the Crisis
}

\author{
Damian S. Damianov \\ Diego Escobari \\ The University of Texas Rio Grande Valley, diego.escobari@utrgv.edu
}

Follow this and additional works at: https://scholarworks.utrgv.edu/ef_fac

Part of the Finance Commons

\section{Recommended Citation}

Damianov, D.S. and Escobari, D. (2021), Getting on and Moving Up the Property Ladder: Real Hedging in the U.S. Housing Market Before and After the Crisis. Real Estate Economics, 49: 1201-1237.

https://doi.org/10.1111/1540-6229.12276

This Article is brought to you for free and open access by the Robert C. Vackar College of Business \& Entrepreneurship at ScholarWorks @ UTRGV. It has been accepted for inclusion in Economics and Finance Faculty Publications and Presentations by an authorized administrator of ScholarWorks @ UTRGV. For more information, please contact justin.white@utrgv.edu, william.flores01@utrgv.edu. 


\title{
Getting on and moving up the property ladder: Real hedging in the U.S. housing market before and after the crisis*
}

\author{
Damian S. Damianov ${ }^{\dagger} \quad$ Diego Escobari ${ }^{\ddagger}$
}

February 11, 2019

\begin{abstract}
Real hedging is the practice of getting onto the property ladder in order to trade up to a larger home in the future. We define the value of the real hedge of home ownership as the difference between the risk premiums of renting and owning and explore how this value depends on local housing price dynamics and household characteristics. Controlling for the potential endogeneity of housing bubble bursts across different U.S metropolitan areas, we find a significantly higher correlation in the appreciation rates across the Standard \& Poor's Case-Shiller tiered house price indices in the period after the housing crisis. We conclude that real hedging has become more attractive in the period after the crisis, particularly in markets exhibiting momentum and high volatility in returns.
\end{abstract}

Keywords: Housing prices, Price tiers, Dynamic correlation, Real hedging

JEL Classifications: C32, G11, R32

${ }^{*}$ We are thankful for the comments by Anurag Banerjee, Anthony Pennington-Cross, Dennis Jansen, Federica Teppa, Yildiray Yildirim, as well as participants at the 2017 AREUEA National Conference in Washington DC, the 2017 AREUEA International Conference in Amsterdam, the 2017 Annual Meeting of the Financial Management Association in Boston, the workshop on real estate finance at Durham University, as well as seminar participants at Texas A\&M University.

${ }^{\dagger}$ Department of Economics \& Finance, Durham University, Mill Hill Lane, Durham DH1 3LB, UK, Phone: +44 (0) 191-33-45528, Fax: +44 (0) 191-33-45201, Email: damian.damianov@durham.ac.uk

${ }^{\ddagger}$ Department of Economics \& Finance, The University of Texas Rio Grande Valley, Edinburg, TX 78539, USA, Phone: +1 (956) 665-2104, Fax: +1 (956) 665-5020, Email: diego.escobari@utrgv.edu, URL: http://faculty.utrgv.edu/diego.escobari

This article has been accepted for publication and undergone full peer review but has not been through the copyediting, typesetting, pagination and proofreading process, which may lead to differences between this version and the Version of Record. Please cite this article as doi: $10.1111 / 1540-6229.12276$

This article is protected by copyright. All rights reserved. 


\section{Introduction}

Buying a home is among the most significant and expensive transactions in the lifetime of a family. When viewed as a purely investment asset, home ownership appears quite risky. The highly leveraged position that a household typically takes in the form of mortgage debt amplifies the effect of house price volatility on its balance sheet. Housing, however, also constitutes a major expense for households that are renting. Englund et al. (2002) report that in Western Europe and North America the average household spends 25 to 35 percent of its income on housing services, a share that is even larger for young families. ${ }^{1}$ When viewed as durable consumption goods, homes guarantee a continuous stream of housing services to prospective buyers in exchange for a known up-front price. Sinai and Souleles (2005) argue that all households are born "short" on housing services since they have to live somewhere, and homes can be viewed as long-lived assets that provide stochastic dividends equal to future rents. Home ownership, thus, serves as a hedge against rent risk because an increase or decrease in rents would be offset by the commensurate appreciation or depreciation of home values.

Home ownership also enables households to move up the property ladder over their life cycle. A young family owning a condominium now could be in a better position to transition to ownership of a single family home compared to a family that is currently renting. In a market with rising home values, the equity accumulated in the condominium allows the young couple to finance the down payment on a single family home. Following Han (2008), in this paper we will refer to the strategy of getting on and moving up the property ladder as "real hedging." When the correlation between appreciation rates of "starter" and "trade-up" homes increases, the economic value of the real hedge increases as well. The real hedge serves the same purpose as a financial hedge where a company buys an asset today that is positively correlated with a commodity required in the future in order to reduce the risk associated with the commodity's future price volatility.

In this paper we examine the economic value of real hedging in U.S. local real estate markets in the periods before and after the housing crisis. We present a theoretical frame-

\footnotetext{
${ }^{1}$ According to an estimate by Zillow, Inc. the U.S. share of income spent on rent for the fourth quarter of 2006 stands at $29.2 \%$ while the historical share for the time period $1985-2000$ stands at $25.8 \%$.
}

This article is protected by copyright. All rights reserved. 
work in which the value of real hedging for a household depends on the variance of its lifetime housing costs as it buys a starter home and subsequently moves up the property ladder. The model allows us to explore how the value of the real hedge depends on key characteristics of housing market dynamics including volatility, momentum, and correlation between the appreciation rates of housing market segments in the same metropolitan area. $^{2}$

As a proxy for the property ladder in U.S. metropolitan residential housing markets, we use the Standard \& Poor's Case-Shiller seasonally adjusted tiered price indices. These monthly price indices are tracking the three segments of local housing markets - low, middle, and high - and are available since the early 1990s for seventeen major metropolitan areas. As the data coverage includes sufficiently long time periods prior to and after the subprime crisis and the Great Recession, it allows us to examine how the dynamic interaction between each pair of price tiers in these markets changes after the crisis.

To get a sense of how the effectiveness of the real hedge depends on key parameters, we develop a theoretical framework that captures three widely documented features of housing price dynamics. First, the appreciation rates of homes are driven by momentum. That is, the returns of each price tier are serially correlated. Starting with Case and Shiller's $(1989,1990)$ seminal articles on the predictability of house prices, a number of studies have reported positive and significant autocorrelation coefficients in various dynamic specifications of real estate returns (see e.g. Abraham and Hendershott, 1993, 1996; Capozza and Seguin, 1996; Capozza et al., 2004). ${ }^{3}$ Following this literature, we assume that housing returns are governed by an autoregressive process which can vary by price tier. Further, we allow for different price tiers to have different return volatility. This feature is pertinent to the boom and bust cycle of the past decade: for the majority of metropolitan areas, low

\footnotetext{
${ }^{2}$ While some families relocate to another residential market, in our empirical analysis we focus on moves within the same local residential market as such moves are most common. Based on data from the Panel Study of Income Dynamics, Han (2008) reports that $62 \%$ of first time buyers traded up by buying a more expensive house in real terms, and from those $71.3 \%$ moved within the same metropolitan area. An analysis of moves across different metropolitan areas and correlation estimates across geographically different markets are presented in Sinai and Souleles (2013).

${ }^{3}$ Building on these results, more recent studies examined potential gains of momentum investment strategies in real estate assets (Beracha and Skiba, 2011; Guren, 2018).
}

This article is protected by copyright. All rights reserved. 
tier homes appreciated the most in the run up and depreciated the most during the bust of the market (Damianov and Escobari, 2016). ${ }^{4}$ Finally, we allow for the returns across tiers in the same metropolitan area to be correlated. ${ }^{5}$ For a home buyer exhibiting constant relative risk aversion over non-housing consumption, the insurance risk premium associated with the real hedging strategy - which we refer to as the "value of the real hedge" - is proportional to the difference in the variances associated with home ownership and renting. The model allows us to analyze how changes in these parameters affects the value of real hedges. As expected, an increase in the correlation between price tiers increases the value of the real hedge. Further, we demonstrate that an increase in the correlation between the tiers improves the value of the real hedge more in markets exhibiting a higher momentum of returns and in high home value markets. Finally, we show that an increase in the correlation coefficient increases the value of the real hedge more in markets with a smaller difference between the tiered price indices.

We use this theoretical framework to derive the value of real hedging for major U.S. metropolitan areas. In particular, we estimate the time-varying conditional correlations across price tiers, their volatilities, as well the level of persistence in their returns by using the multivariate DCC-GARCH empirical specification proposed by Engle (2002). In line with previous studies, we find that the time series of the tiered indices exhibit persistence. That is, high past appreciation rates are likely to lead to further appreciation, and house price declines are likely to be followed by further declines. These autoregressive processes are best described by models of up to five lags, as selected by the Akaike information criterion. ${ }^{6}$ The DCC specification allows us to obtain dynamic trajectories of the pairwise correlations in returns between the tiers and study their behavior over periods of particular interest. We estimate the effect of the bubble bursts in different metropolitan

\footnotetext{
${ }^{4}$ Previous boom and bust cycles were characterized by greater volatility of high-priced homes. Poterba (1991), for example, analyzes Atlanta, Chicago, Dallas, and Oakland, and reports that, over the time period 1970-1982, houses in the top quartile appreciated faster than the ones in the bottom quartile.

${ }^{5}$ Using data from the National Association of Realtors Existing Home Sale Series, Han (2010) reports a correlation between the prices of condominiums and single family homes in excess of 0.9 .

${ }^{6}$ Markets with a high level of momentum are typically expensive markets such as San Diego, San Francisco, Los Angeles and New York. Markets exhibiting moderate momentum levels include Phoenix, Miami and Washington DC, while markets with a positive yet lower momentum in returns include Denver and Portland. Cleveland is the only market that does not exhibit autocorrelation in returns.
}

This article is protected by copyright. All rights reserved. 
areas by analyzing the correlation coefficients using a dynamic panel system Generalized Method of Moments (GMM) estimator. The pooled, the fixed effect, and the dynamic panel estimates show a statistically and economically significant increase in the correlation between the price tiers after the bubble burst which suggests a substantial improvement in the economic value of real hedging in the post-crisis period.

\section{Related literature}

This paper relates to the growing theoretical and empirical literature on the hedging value of home ownership. The role of home ownership as insurance against fluctuations in future housing cost has been explored in several prior theoretical papers (see e.g. Han, 2008, Ortalo-Magné and Rady, 2002, Sinai and Souleles, 2005, and Ortalo-Magné and Pratt, 2016). The present framework is most closely related to the model by Sinai and Souleles (2005) in that it considers the current tenure decision of a household which intends to relocate in the future. Sinai and Souleles (2005) assume that rents - interpreted as dividends to home ownership - exhibit persistence: they follow an $\mathrm{AR}(1)$ process and house prices adjust in such a way as to leave households indifferent between renting and owning. One consequence of these assumptions is that equilibrium house prices, corresponding to the sum of risk-adjusted discounted expected future rents, can be expressed as linear functions of contemporaneous rents and, hence, also follow an $\mathrm{AR}(1)$ process. We, in contrast, in line with the literature on market momentum, assume that the house price appreciation rates, rather than the house prices, follow an autoregressive process, whereby we allow for a general $\operatorname{AR}(q)$ process. This more general formulation of return dynamics allows us to explore how momentum shapes the volatility of housing market returns of different housing market segments. In addition, it allows us to examine how our results relate to the extant literature on momentum in housing returns.

The early literature on momentum views the positive autocorrelation in housing returns as evidence that the market for single-family homes is not informationally efficient. Using data for Atlanta, Chicago, Dallas and San Francisco over the 1970-1986 time period, Case and Shiller $(1989,1990)$ find that price changes in one year are likely to continue in the same direction for one additional year. In the current study, we use monthly data on seventeen

This article is protected by copyright. All rights reserved. 
metropolitan areas including Atlanta, Chicago and San Francisco. For these three cities we find that the market momentum implied by the autocorrelation in monthly returns amplifies return volatility by a factor between one than two.

The magnitude and the causes for momentum in housing market returns have received much attention in the literature. Using quarterly data from Hong Kong, Fu and Ng (2001) finds that momentum is due to slow response of house prices to new information. More recently, using data from San Francisco, Los Angeles, and San Diego over the 2008-2013 time period, Guren (2018) shows that momentum can be explained by the strategic behavior of sellers who find it optimal to set asking prices close to the existing average market price. Chauvet et al. (2016) estimate autoregressive models using monthly returns over the same time period, yet include a larger number of metropolitan areas. They find that the autoregressive coefficients for the first two lags are positive while for the third lag is negative. We report here similar results which are robust both to the geographical area and the house price tier considered. The recent literature on market momentum has also taken on a variety of other approaches. Following the study by Jegadeesh and Titman (1993) on momentum in stock market returns, Beracha and Skiba (2011) construct long-short zero cost investment portfolios based on lagged residential real estate returns. They find that the strategy of buying winners and selling losers indeed generates positive returns. Piazzesi and Schneider (2009) use data from the Michigan Survey of Consumers to explore how households' beliefs about future house price appreciation are formed during the housing market boom of the early 2000s.

The present paper also relates to the literature exploring whether households can insure themselves through home ownership. Han (2010) differentiates between financial risk effect on demand associated with price volatility and hedging effect on demand associated with correlation between current and desired future houses. She finds evidence for self-insurance behavior: timing and size of home purchases are related to the strength of households' hedging incentives, whereby hedging incentives are associated with the geographical mobility of the household and its tendency to trade up. Amior and Halket (2014) report that home ownership rates and loan-to-value ratios at the city level are negatively correlated with house price volatility, while Sinai and Souleles (2005) show that price-to-rent ratios and the probability of home ownership are positively related to the volatility of rents. In a

This article is protected by copyright. All rights reserved. 
more recent related empirical work, Sinai and Souleles (2013) find that, when households move across different metropolitan areas, they tend to move between highly correlated markets. This leads them to conclude that the "moving-hedge" value of owning would be higher than the one predicted by the average level of correlation between metropolitan areas.

In this paper, in contrast, we consider the value of real hedging for households that have the intention to move to a different tier in the same metropolitan area - a scenario corresponding to the behavior of the majority of first time buyers (Han, 2008). Using a dynamic specification, we find a significant increase in the correlation across tiers, which implies a higher economic value of real hedging for the period after the mortgage crisis.

\section{Homeownership as a real hedge}

We consider a local housing market in which the appreciation rates of different house price tiers are governed by a general $A R(q)$ process where $q$ denotes the number of lags in the model. Our theoretical framework allows for persistence in the appreciation rates, contemporaneous correlation across tiers, and different volatility of the monthly returns of different housing market segments. In the following sections we estimate the parameters of this model and use them to calculate the value of the real hedging strategy. That is, we place a household with specific preferences in a given local housing market and derive the hedging value of home ownership as a function of model estimates and household preferences.

House price dynamics. For ease of exposition, let us denote the price of the (low) tier $i$ in month $t$ by $P_{t}^{i}$ and the price of the (middle) tier $j$ in month $t$ by $P_{t}^{j}$. Denoting their $\operatorname{logarithms}$ by $p_{t}^{i} \equiv \log \left(P_{t}^{i}\right)$ and $p_{t}^{j} \equiv \log \left(P_{t}^{j}\right)$, we express the monthly house price appreciation rates as $r_{t}^{i}=p_{t}^{i}-p_{t-1}^{i}$ and $r_{t}^{j}=p_{t}^{j}-p_{t-1}^{j}$. Housing returns are assumed to follow a general $A R(q)$ process given by

$$
\begin{aligned}
& r_{t}^{i}=\mu_{i}+\sum_{h=1}^{q} \varphi_{h}^{i} r_{t-h}+\varepsilon_{t}^{i}, \\
& r_{t}^{j}=\mu_{j}+\sum_{h=1}^{q} \varphi_{h}^{j} r_{t-h}+\varepsilon_{t}^{j},
\end{aligned}
$$

This article is protected by copyright. All rights reserved. 
where $\varepsilon_{t}^{i} \sim N\left(0, \sigma_{i}^{2}\right), \varepsilon_{t}^{j} \sim N\left(0, \sigma_{j}^{2}\right)$ and $\operatorname{corr}\left(\varepsilon_{t}^{i}, \varepsilon_{t}^{j}\right)=\rho$. Hereby $\mu_{i}$ and $\mu_{j}$ are constant terms and $\varphi_{h}^{i}$ and $\varphi_{h}^{j}$ are the autoregressive terms in the above equations. The volatilities of the appreciation rates of the two price tiers are denoted by $\sigma_{i}$ and $\sigma_{j}$, respectively and their contemporaneous correlation by $\rho$. In the following section, we estimate these parameters for the local markets covered by the Standard \& Poor's Case-Shiller tiered house price indices.

Real hedging volatility. A household plans to reside in a local housing market and occupy a low tier home for a number of $T$ years upon which to transition to a middle tier home in the same area for another $T$ years. We will refer to such a household as a household with a time horizon $T$ and will compare homeownership (real hedging) with renting in this setting.

The household has a present value of lifetime earnings $W$ and can invest in hypothetical instruments pegged to the value of housing in each tier. If the current prices of the low tier and the middle tier homes are $P_{i}$ and $P_{j}$, the portfolio weights for investment in the low tier and middle tier are $\omega_{i}=\frac{P_{i}}{W}$ and $\omega_{j}=\frac{P_{j}}{W}$, respectively. As the real hedging strategy involves selling the low tier home and buying the middle tier home in year $T$, the return volatility associated with this strategy corresponds to the volatility of a portfolio consisting of a long position in the low tier home and a short position in the middle tier home. Hence the variance of the cumulative return for the first $T$ periods of the real hedging strategy is given by

$$
\bar{\sigma}_{O W N}^{2}\left(\omega_{i}, \omega_{j}, T\right)=\omega_{i}^{2} \cdot\left(\bar{\sigma}_{i, T}^{2}\right)+\omega_{j}^{2} \cdot\left(\bar{\sigma}_{j, T}^{2}\right)-2 \cdot\left(\omega_{i} \cdot \omega_{j}\right) \cdot \rho \cdot\left(\bar{\sigma}_{i, T}\right)\left(\bar{\sigma}_{j, T}\right)
$$

Hereby $\bar{\sigma}_{\tau, T}^{2}=\operatorname{var}\left(\sum_{t=1}^{12 T} r_{t}^{\tau}\right)$ where $\tau=i, j$ denote the variances of the cumulative returns of investing in the low tier and the middle tier homes for the first $T$ years. Further, as the middle tier home is bought in year $T$ and held up to year $2 T$, the volatility of final wealth in year $2 T$ is determined by the long position in the middle tier home. Thus the variance of the cumulative return of the real hedging portfolio at the end of year $2 T$ is given by

$$
\bar{\sigma}_{O W N}^{2}\left(\omega_{j}, 2 T\right)=\omega_{j}^{2} \cdot\left(\bar{\sigma}_{j, 2 T}^{2}\right),
$$

where $\bar{\sigma}_{j, 2 T}^{2}=\operatorname{var}\left(\sum_{t=1}^{24 T} r_{t}^{j}\right)$.

We next explore how the variance of the cumulative return for a given period of $T$

This article is protected by copyright. All rights reserved. 
years depends on the autoregressive estimates of the empirical model. For notational convenience, in the following exposition we will suppress the price tier index $\tau$ when denoting the cumulative return of particular price tier, i.e. we will use $\sigma_{T}^{2}$ instead of $\sigma_{\tau, T}^{2}$. Similarly, we use $\varphi_{h}$ instead of $\varphi_{h}^{\tau}$ and $\sigma^{2}$ instead of $\sigma_{\tau}^{2}$. The variance of the cumulative return for $T$ years is given by

$$
\bar{\sigma}_{T}^{2}=\sum_{s=1}^{12 T} \sum_{m=1}^{12 T} \operatorname{cov}\left(r_{s}, r_{m}\right)=\sum_{s=1}^{12 T} \sum_{m=1}^{12 T} \sigma_{s} \cdot \sigma_{m} \cdot \varrho_{|m-s|} .
$$

Hereby $\sigma_{s}$ and $\sigma_{m}$ are the volatilities of the returns in months $s$ and $m$, respectively and $\varrho_{|m-s|}$ is the autocorrelation between these returns. The autocorrelations satisfy the YuleWalker system of equations

$$
\varrho_{l}=\varphi_{1} \cdot \varrho_{l-1}+\varphi_{2} \cdot \varrho_{l-2}+\cdots+\varphi_{q} \cdot \varrho_{l-q},
$$

where $l$ denotes the autoregressive lag. Using the property $\varrho_{l}=\varrho_{-l}$ we obtain the first $q$ autocorrelation terms by solving the system of equations

$$
\left[\begin{array}{ccccc}
1 & \varrho_{1} & \varrho_{2} & \cdots & \varrho_{q-1} \\
\varrho_{1} & 1 & \varrho_{1} & \cdots & \varrho_{q-2} \\
\vdots & \vdots & \vdots & \ddots & \vdots \\
\varrho_{q-1} & \varrho_{q-2} & \varrho_{q-3} & \cdots & 1
\end{array}\right]\left[\begin{array}{c}
\varphi_{1} \\
\varphi_{2} \\
\vdots \\
\varphi_{q}
\end{array}\right]=\left[\begin{array}{c}
\varrho_{1} \\
\varrho_{2} \\
\vdots \\
\varrho_{q}
\end{array}\right]
$$

The terms $\varrho_{l}$ for $l>q$ are derived iteratively by equation (6) once we solved for $\varrho_{1}, \varrho_{2}, \ldots, \varrho_{q}$. The variance $\sigma_{t}^{2}$ for $t=1,2, \ldots, 12 T$ is given by

$$
\sigma_{t}^{2}=\operatorname{var}\left(\varphi_{1} r_{t-1}+\cdot+\varphi_{q} r_{t-q}+\varepsilon_{t}\right)
$$

It can be derived iteratively using the relationship

$$
\sigma_{t}^{2}=\left[\begin{array}{lll}
\varphi_{1} & \ldots & \varphi_{q}
\end{array}\right]\left[\begin{array}{cccc}
\sigma_{t-1} \sigma_{t-1} & \varrho_{1} \cdot \sigma_{t-1} \sigma_{t-2} & \ldots & \varrho_{q-1} \cdot \sigma_{t-1} \sigma_{t-q} \\
\varrho_{1} \cdot \sigma_{t-2} \sigma_{t-1} & \sigma_{t-2} \sigma_{t-2} & \ldots & \varrho_{q-2} \cdot \sigma_{t-2} \sigma_{t-q+1} \\
\vdots & \vdots & \ddots & \vdots \\
\varrho_{q-1} \cdot \sigma_{t-q} \sigma_{t-1} & \varrho_{q-1} \cdot \sigma_{t-q+1} \sigma_{t-2} & \ldots & \sigma_{t-q} \sigma_{t-q}
\end{array}\right]\left[\begin{array}{c}
\varphi_{1} \\
\vdots \\
\varphi_{q}
\end{array}\right]+\sigma^{2} .
$$

We note that $\sigma_{t}^{2}=0$ for $t<0$ as the past realizations of returns are observed and that

This article is protected by copyright. All rights reserved. 
$\sigma_{1}^{2}=\operatorname{Var}\left(\varepsilon_{t}\right)=\sigma^{2} \cdot{ }^{7}$ For a general stationary $A R(q)$ process, the Yule-Walker conditions yield the following relationship between the error term variance and the variance of the process:

$$
\sigma_{A R(q)}^{2}=M\left(\varphi_{1}, \ldots, \varphi_{q}\right) \cdot \sigma^{2}
$$

where

$$
M\left(\varphi_{1}, \ldots, \varphi_{q}\right)=\frac{1}{\varphi_{1} \varrho_{1}+\varphi_{2} \varrho_{2}+\cdots+\varphi_{q} \varrho_{q}} .
$$

We refer to $M\left(\varphi_{1}, \ldots, \varphi_{q}\right)$ as "market momentum" and calculate it for the metropolitan areas in our empirical analysis. ${ }^{8}$ With this definition of momentum, the variance of the cumulative return over $T$ periods presented in equation (5) can be approximated by

$$
\bar{\sigma}_{T}^{2} \approx M\left(\varphi_{1}, \ldots, \varphi_{q}\right) \cdot \sigma^{2} \cdot\left[12 T+2 \cdot \sum_{t=1}^{12 T-1}(12 T-t) \varrho_{t}\right] .
$$

We use this cumulative return variance in our analysis of the value of real hedging.

Value of real hedge. A complete analysis of the attractiveness of home ownership would take into account an array of relevant issues which are assumed away in the current model. These include transaction costs, tax implications, depreciation rates, leverage and down payment requirements, labor income, inflation, interest rate risk, etc. We abstract from these features here for the sake of tractability as our main focus is on the potential hedging benefits of home ownership. Yet, these factors are important; they operate alongside the

\footnotetext{
${ }^{7}$ For an $A R(1)$ process the solution to the model is given in a closed form. The Yule-Walker conditions yield for the autocorrelation $\varrho_{l}=\varphi_{1}^{l}$. The variance of the return in period $t$ is given by

$$
\sigma_{t}^{2}=\sigma^{2} \sum_{s=1}^{t} \varphi_{1}^{2(s-1)}=\sigma^{2} \frac{\left(1-\varphi_{1}^{2 t}\right)}{1-\varphi_{1}^{2}}
$$

and the variance of the cumulative return up to period $T$ is given by

$$
\bar{\sigma}_{T}^{2}=\sum_{s=1}^{12 T} \sum_{m=1}^{12 T} \sigma_{s} \cdot \sigma_{m} \cdot \varphi_{1}^{|m-s|} .
$$

As can easily be established, for any time horizon $T$, this variance is increasing in the autoregressive coefficient $\varphi_{1}$ when this coefficient is positive. Hence, the persistence of the time series amplifies the volatility of the cumulative return because a high return in the current period implies a higher cumulative expected return. This intuition carries over to general $A R(q)$ processes only as long as the autoregressive coefficients and the autocorrelations in the model are positive. This is the case for some but not all metropolitan markets.

${ }^{8}$ The momentum of an $A R(1)$ process is $D\left(\varphi_{1}\right)=\frac{1}{1-\varphi_{1}^{2}}$.
}

This article is protected by copyright. All rights reserved. 
hedging incentives analyzed here, and have been the focus of prior studies. ${ }^{9}$ As we consider home ownership as a form of insurance against fluctuations in housing costs for the household, we define the value of the real hedge as the difference in the risk premiums implied by the two tenure modes.

We view the household choice of buying versus renting as a standard portfolio choice of a risk averse investor. If the household decides to rent for its entire life span of $2 T$ years, it will be exposed to rent uncertainty in each period in which its lease contract is up for renewal. As the majority of rental contracts are for lease terms of one year or less, ${ }^{10}$ we assume that lease contracts are renewed on an annual basis. ${ }^{11}$ Home ownership eliminates the risk associated with uncertainty in rents but exposes the household to house price risk. This exposure occurs at moment $T$ when the household sells the low tier home and buys the middle tier home and at the end of the final period 2T. Given that these transactions occur in the relatively distant future, it is possible that the risk of owning, measured in present value terms, is lower than the risk of renting. Thus, risk premiums depend on the housing market parameters and the characteristics of the household. Let us consider a household exhibiting constant relative risk aversion which discounts future risk premiums exponentially. The characteristics of this household are summarized by

$$
Z_{h}=(\theta, \delta, W, T)
$$

where $\theta$ is the risk aversion coefficient, $\delta$ is the annual discount factor, $W$ is the lifetime wealth of the household, and $T$ is the time horizon (measured in years). The housing market characteristics are captured by

$$
Z_{m}=\left(\bar{\sigma}_{i, T}^{2}, \bar{\sigma}_{j, T}^{2}, \rho, d_{i}^{2}, d_{j}^{2}\right) .
$$

\footnotetext{
${ }^{9}$ The effects of transaction cost on the timing and size of home ownership have been analyzed by Han (2008) and Flavin and Nakagawa (2008). The implications for portfolio choice have been studied by Engle (2002), Flavin and Yamashita (2002), and Hu (2005). The effects of down payment constraints have been discussed in Stein (1995) and Lustig and Nieuwerburgh (2005). Uncertainty in labor income has been considered by Ortalo-Magné and Rady (2002) and Davidoff (2006). More recently, Campbell and Cocco (2015) study mortgage decision by incorporating a number of these factors, including inflation, house price uncertainty, and interest rate risk.

${ }^{10}$ Using data from the Annual Housing Survey, Genesove (2003) reports that only $3 \%$ of residential leases are for terms longer than a year.

${ }^{11}$ The framework can be easily adapted to consider alternative lease terms, e.g. 6 months.
}

This article is protected by copyright. All rights reserved. 
Hereby $\bar{\sigma}_{i, T}^{2}$ and $\bar{\sigma}_{j, T}^{2}$ are the cumulative return variances of the low tier and middle tier home, respectively over a time horizon of $T$. The parameter $\rho$ represents the contemporaneous correlation between the monthly appreciation rates of the price tiers, and $d_{i}^{2}$ and $d_{j}^{2}$ are the volatilities of the annual rents of the two price tiers. The risk premium of home ownership is given by

$$
\Theta_{O W N}\left(Z_{m}, Z_{h}\right):=\frac{\theta}{2} \cdot\left[\delta^{T}\left(\bar{\sigma}_{O W N}^{2}\left(\omega_{i}, \omega_{j}, T\right)\right)+\delta^{2 T}\left(\bar{\sigma}_{O W N}^{2}\left(\omega_{j}, 2 T\right)\right)\right] .
$$

The first term is associated with the variance of selling the low tier home and buying the middle tier home in period $T$ while the second term is associated with the variance of the middle tier home in the final period $2 T$. The risk for a renter stems from the volatility of annual rent as a proportion of annual earnings $W_{a}$ and is given by

$$
\Theta_{R E N T}\left(Z_{m}, Z_{h}\right):=\frac{\theta}{2} \cdot\left[\sum_{n=1}^{T} \delta^{n} \cdot \frac{d_{i}^{2}}{W_{a}^{2}}+\sum_{n=T+1}^{2 T} \delta^{n} \cdot \frac{d_{j}^{2}}{W_{a}^{2}}\right] .
$$

With these preliminaries, the value of the real hedge is defined as

$$
V\left(Z_{m}, Z_{h}\right):=\Theta_{R E N T}\left(Z_{m}, Z_{h}\right)-\Theta_{O W N}\left(Z_{m}, Z_{h}\right)
$$

The real hedge has a positive value when home ownership is less risky than renting. In the next sections we estimate the housing market parameters for the periods before and after the burst of the bubble and discuss how the value of real hedging has changed after the housing market crisis.

\section{Data and preliminary evidence}

\subsection{Data}

In this study we use the Standard \& Poor's CoreLogic Case-Shiller (CS) seasonally adjusted tiered-price indices as a measure of the dynamics of different house price segments in local residential real estate markets. The CS tiered indices are constructed using a repeat sales methodology which is based on the forming of pairs of recorded prices from arms-length transactions of the same property. The repeat sales methodology is designed to track changes in home values due to market trends only. It controls for physical alterations in individual houses and neighborhoods, corrects for biases due to statistical outliers, to 
the variation in frequency of sales, to delays in the flow of transaction data, as well as to potential sampling and measurement errors. The CS price tiers capture changes in home values of three market segments in each MSA - low, middle, and high. To construct the tiered indices, the CS method selects price breakpoints between low-tier and middle-tier houses and between middle-tier and upper-tier houses. The breakpoints are established in such a way that the same number of sales occurs in each price tier and are smoothed through time to eliminate seasonal and other transient variation. ${ }^{12}$

The CS tiered indices were established in January 1987 for ten metropolitan markets; seven additional residential areas were included over the time period between January 1989 and January 1993. Our sample consists of all the seventeen Metropolitan Statistical Areas (MSA) for which the price tiers are available (i.e., Atlanta, Boston, Chicago, Cleveland, Denver, Las Vegas, Los Angeles, Miami, Minneapolis, New York, Phoenix, Portland, San Diego, San Francisco, Seattle, Tampa, and Washington DC).

[Table 1, about here]

Each series in our sample begins when it was first established and ends in June 2016. Only one residential area, Cleveland, ends earlier as it was discontinued in November 2008. In Table 1 we present the mean and the standard deviation of the appreciation rates for the low-tier $\left(r_{t}^{i}\right)$, middle-tier $\left(r_{t}^{j}\right)$ and the high-tier $\left(r_{t}^{k}\right)$ indices of all MSAs in the sample. The upper panel in the table shows the statistics for the period before the bubble burst, while the lower panel shows the period after the bubble burst. The month of the bubble burst is defined as the month at which the low tier index reached its maximum value.

\section{[Figure 1, about here]}

To illustrate the dynamics of the price tiers during the period of study, we present in Figure 1 the low-, middle-, and high-tier indices for two of the metropolitan areas: Miami

\footnotetext{
${ }^{12}$ The construction of the CS tiered indices and the repeat sales methodology are described in S\&P Dow Jones Indices: S\&P CoreLogic Case-Shiller Home Price Indices Methodology, April 2017, available from http://us.spindices.com/documents/methodologies/methodology-sp-cs-home-price-indices.pdf. A discussion of the advantages and potential concerns of using the CS indices in research as well as a comparison of the CS index to other indices (e.g., the Home Price Index published by the Federal Housing Finance Agency) is presented in Miao et al. (2011).
}

This article is protected by copyright. All rights reserved. 
and Los Angeles. The vertical lines mark the burst of the bubbles. All indices are adjusted to have January 1987 as their base month. Two apparent observations can easily be made from examining these figures. First, all tiers increased during the housing bubble years and then started to decrease almost simultaneously once the housing bubble burst. And second, the low tier increased the most during the bubble period, and decreased the most after the bubble burst. The price dynamics presented in Figure 1 is quite typical across metropolitan areas and is consistent with the lower average appreciation rates for high tier homes reported in Panel A of Table 1.

\subsection{Preliminary evidence}

Table 2 offers a first impression the significance of real hedging for households and of the way hedging incentives have changed after the recent housing crisis. The table reports the unconditional correlations between the appreciation rates of the high tier and the S\&P 500 (columns 1 and 2) as well as the unconditional correlations between the appreciation rates of the high tier and the low tier (columns 7 and 8). We observe that the unconditional correlations between the price tiers are positive and substantially larger in magnitude than the correlations between each price tier and the $\mathrm{S} \& \mathrm{P} 500$. This is an indication that stock market participation is not as effective as real hedging for households who intend to move up the property ladder in the same metropolitan area.

Further, the reported z-statistics in column 7 are associated with the null hypothesis that the correlations are the same before and after the burst, while the alternative is that the correlation is smaller before the bubble burst. The associated p-values show that at the $10 \%$ significance level for eight of the seventeen metropolitan areas the correlation between the high and low tiers is stronger after the bubble burst. A similar conclusion can be drawn when considering the correlation between the high tier and the S\&P 500. With the exception of Portland and Seattle, the correlations are statistically larger after the burst. While the reported statistics do not take into account the dynamics of the correlations over time, they provide some evidence that correlations have increased after the crisis. As we demonstrate in the following sections, the increase in the correlations is statistically significant in the studied empirical models that take into account conditional correlation dynamics.

This article is protected by copyright. All rights reserved. 


\section{The dynamic correlation-coefficient model}

\subsection{Formulation of price tiers}

To account for the dynamics of the appreciation rates of the different price tiers we employ the multivariate GARCH methods developed in Engle (2002). We denote by $P_{m t}^{\tau}$ the index in metropolitan area $m$ in period $t$ for tier $\tau=(i, j, k)$ where $i, j$, and $k$ signify the low, middle, and high tier, respectively. With the notation introduced previously, we calculate the returns and express them in percentage terms as follows: $r_{m t}^{\tau}=\left[\log \left(P_{m t}^{\tau}\right)-\right.$ $\left.\log \left(P_{m, t-1}^{\tau}\right)\right] \cdot 100$. To simplify notation we further drop the subscript $m$ and present the empirical approach for a given metropolitan area.

As noted by Chiang et al. (2007), there are three advantages of using Engle's (2002) model. First, the estimation is robust to heteroscedasticity as the DCC-GARCH model estimates the correlation coefficients of the standardized residuals. Second, the empirical model allows for the inclusion of additional regressors in the mean equation. In our case we use the U.S. S\&P 500 stock returns as a common factor that potentially affects all price tiers. Third, it is well known that the estimation of the dynamic correlations is particularly difficult because of the large number of coefficients in the variance-covariance matrix, for example, in the methods described in Engle and Kroner (1995). The approach suggested by Engle (2002) allows the inclusion of multiple returns without the need to estimate too many coefficients. The estimation output includes time-varying correlation coefficients that affords the analysis of regime shifts.

We model the vector of appreciation rates $r_{t}=\left(r_{t}^{i}, r_{t}^{j}, r_{t}^{k}\right)^{\prime}$ in the mean equation as an $\operatorname{AR}(q)$ process. In particular, we use the specification:

$$
r_{t}=\mu+\sum_{h=1}^{q} \varphi_{h} r_{t-h}+\gamma r_{t-1}^{\mathrm{S \& P} 500}+\varepsilon_{t}
$$

where $\mu=\left(\mu_{i}, \mu_{j}, \mu_{k}\right), \varphi_{h}=\left(\varphi_{h}^{i}, \varphi_{h}^{j}, \varphi_{h}^{k}\right), \gamma=\left(\gamma_{i}, \gamma_{j}, \gamma_{k}\right), \varepsilon_{t}=\left(\varepsilon_{t}^{i}, \varepsilon_{t}^{j}, \varepsilon_{t}^{k}\right)$, and $\varepsilon_{t} \mid \Omega_{t-1} \sim$ $N\left(0, H_{t}\right) .{ }^{13}$ Note that Equation (11) is simply the vector version of Equations (1) and (2) with an additional third equation for the high tier and the lagged S\&P 500 stock return. We add the autoregressive term in order to capture momentum effects. The control $r_{t-1}^{\text {S\&P500 }}$ serves as a factor that can potentially affect all returns and as an alternative investment

\footnotetext{
${ }^{13}$ With $\Omega_{t-1}$ being the information set available at the end of period $t-1$.
}

This article is protected by copyright. All rights reserved. 
opportunity. A key objective of the analysis is to model the dynamics of the variancecovariance matrix $H_{t}$. We use the following specification for this conditional variance:

$$
H_{t}=D_{t} R_{t} D_{t}
$$

where both $D_{t}$ and $R_{t}$ are time-varying. $R_{t}$ is the $(3 \times 3)$ correlation matrix of interest, while $D_{t}$ is a $(3 \times 3)$ diagonal matrix. The three diagonal elements in $D_{t}$, denoted by $\sqrt{h_{t}^{\tau}}$, $\tau=(i, j, k)$ represent the standard deviations from separately fitted univariate GARCH models.

We use a two-stage approach to estimate the variance-covariance matrix $H_{t}$. In the first stage, estimates of $\sqrt{h_{t}^{\tau}}$ are obtained by fitting univariate volatility models for each price tier. In the second stage, the residuals from the first stage are transformed using $u_{t}^{\tau}=\varepsilon_{t}^{\tau} / \sqrt{h_{t}^{\tau}}$, upon which the parameters of the dynamic conditional correlation model are estimated. We use Engle's (2002) model specification for the evolution of the conditional correlations given by:

$$
Q_{t}=(1-\alpha-\beta) \bar{Q}+\alpha u_{t-1} u_{t-1}^{\prime}+\beta Q_{t-1},
$$

where $\alpha$ and $\beta$ are nonnegative parameters to be estimated under the restriction $(\alpha+\beta)<1$. The $3 \times 3$ unconditional variance-covariance matrix of $u_{t}$ is given by $\bar{Q}=E\left[u_{t} u_{t}^{\prime}\right]$, while $Q_{t}$ is the $3 \times 3$ time-varying conditional variance-covariance matrix of $u_{t}$. To obtain ones in the main diagonal of the correlation matrix $R_{t}$, we rescale $Q_{t}$ as follows:

$$
R_{t}=\operatorname{diag}\left(\frac{1}{\sqrt{\nu_{t}^{i}}}, \frac{1}{\sqrt{\nu_{t}^{j}}}, \frac{1}{\sqrt{\nu_{t}^{k}}}\right) Q_{t} \operatorname{diag}\left(\frac{1}{\sqrt{\nu_{t}^{i}}}, \frac{1}{\sqrt{\nu_{t}^{j}}}, \frac{1}{\sqrt{\nu_{t}^{k}}}\right)
$$

where $\nu_{t}^{\tau}$ are the main diagonal elements of $Q_{t}$. If $Q_{t}$ is positive definite, the absolute value of the off-diagonal elements of $R_{t}$ will all be less than one. As an illustration of how the off-diagonal elements of $R_{t}$ are obtained, let us drop the high tier $k$ and consider the bivariate model with only the low tier $i$ and the middle tier $j$. The pairwise correlations represented by the off-diagonal elements of $R_{t}$ will have the form:

$$
\rho_{t}^{i-j}=\frac{(1-\alpha-\beta) \bar{\nu}^{i-j}+\alpha u_{t-1}^{i} u_{t-1}^{j}+\beta \nu_{t-1}^{i-j}}{\sqrt{(1-\alpha-\beta) \bar{\nu}^{i}+\alpha\left(u_{t-1}^{i}\right)^{2}+\beta \nu_{t-1}^{i}} \sqrt{(1-\alpha-\beta) \bar{\nu}^{j}+\alpha\left(u_{t-1}^{j}\right)^{2}+\beta \nu_{t-1}^{j}}},
$$

where $\bar{\nu}^{i-j}$ and $\nu_{t}^{i-j}$ are the single off-diagonal elements of $\bar{Q}$ and $Q_{t}$ respectively. 
The log-likelihood function to be maximized is given by:

$$
l_{t}(\mu, \varphi, \gamma, \vartheta)=-\sum_{t-1}^{T}\left(3 \cdot \log (2 \pi)+\log \left|D_{t}\right|^{2}+\varepsilon_{t}^{\prime} D_{t}^{-2} \varepsilon_{t}\right)-\sum_{t=1}^{T}\left(\log \left|R_{t}\right|+u_{t}^{\prime} R_{t}^{-1} u_{t}-u_{t}^{\prime} u_{t}\right)
$$

with $(\mu, \varphi, \gamma)$ denoting the coefficients to be estimated in $D_{t}$, and $\vartheta$ the coefficients to be estimated in $R_{t}$. The first term on the right-hand side is the sum of the individual GARCH likelihoods. The second term represents the function to be maximized in order to obtain the correlation coefficients. According to the two-step procedure of Engle (2002), in the first estimation step estimates of $(\mu, \varphi, \gamma)$ corresponding to $D_{t}$ are obtained by maximizing the first term on the right-hand side of Equation (16). Given these estimates, in the second step, the second term is maximized to obtain the estimates of $\vartheta$.

\subsection{Dynamic correlation and momentum estimates}

Table 3 reports the estimation results for three of the metropolitan areas in the sample: San Diego, Denver, and Atlanta. We chose these three areas because they have different number of lags according to the Akaike information criterion. ${ }^{14}$ Looking at the estimates of the mean equations we observe that the regression constants $(\mu)$ are all positive and highly significant. As expected, these estimates are close to the respective means of the dependent variable $r_{t}^{\tau}$ reported in Table 1 . We observe that for Denver the point estimates of the regression constants are larger for the low tier than for the high tier - a finding consistent with the well known observation that during the housing bubble the low tier appreciated more than the high tier. Looking at the estimates of the mean equation we further observe that the coefficient $\gamma$ capturing the effect of the $\mathrm{S} \& \mathrm{P} 500$ index on the price tiers is not statistically significant. That is, the U.S. stock market does not significantly affect the price dynamics in local housing markets.

[Table 3, about here]

When examining the variance equations in Panels B, we observe that the lagged shocksquared terms $(b)$ are statistically significant across all metropolitan areas, indicating that volatilities are indeed time-varying. The highly significant coefficients on the lagged conditional volatility $(a)$ lends further support to our GARCH specification. The measure of

\footnotetext{
${ }^{14}$ The number of lags for all metropolitan areas are reported in Table 4.
} 
volatility persistence $a+b$ registers values close to one across all metropolitan areas, which is an indication of high levels of persistence in the conditional variances. To obtain the estimates of $\alpha$ and $\beta$ in the multivariate DCC equations reported in Panels $\mathrm{C}$, we used the second step proposed in Engle (2002). The highly statistically significant $\alpha$ and $\beta$ coefficients across all metropolitan areas are strong evidence of substantial time-varying co-movement across price tiers. The Wald test with the null hypothesis that $\alpha=\beta=0$ provides strong evidence against the null.

While in Table 3, due to space considerations, we present the DCC-GARCH model results for only three of the metropolitan areas, in Table 4 we report the sum of the autoregresive coefficients and the conditional correlations between tiers for all the seventeen metropolitan areas in our sample. With the exception of Cleveland where the data ends in 2008, the sum of the autoregressive terms in the mean equations (i.e., $\sum_{h=i}^{q} \varphi_{h}$ ) are all positive and highly significant. The point estimates are relatively smaller for Chicago and Minneapolis, Portland and Tampa, and are larger for New York and for the metropolitan areas in California. We interpret a positive $\sum_{h=i}^{q} \varphi_{h}$ as evidence for momentum effects and partial adjustments in housing markets.

[Table 4, about here]

Given that within each metropolitan area we have three tiers, our estimation approach allows us to obtain estimates of three pair-wise time-varying correlations, $\rho_{t}^{i-j}, \rho_{t}^{i-k}$, and $\rho_{t}^{j-k}$. To illustrate the dynamics of these pair-wise correlations, we present in Figure 2 the time series graphs for Cleveland and Washington DC. The vertical lines indicate the dates at which $P_{m t}^{i}$ reaches its peak. The averages for these correlations are reported in columns 5 through 7 of Table 4 .

\section{[Figure 2, about here]}

Consistent with the correlations presented in Table 2, the result in Table 4 and Figure 2 show that the dynamic correlations are all positive. ${ }^{15}$

\footnotetext{
${ }^{15}$ The only average correlations that are not significantly different from zero are the ones for Cleveland.
} 


\section{Dynamic correlations and the bubble burst}

\subsection{Panel estimation of the effect of the bubble burst}

In this section we examine whether the housing crisis has affected the value of real hedging by testing for changes in the conditional correlation coefficients. The graphs presented in Figure 2 suggest that the dynamic correlations are higher after the bubble burst. To test this formally we pool the dynamic correlations across all our seventeen metropolitan areas to obtain a panel of correlations. As before, we use $m$ to denote the metropolitan market and estimate a dynamic panel specification of the following form:

$$
\rho_{m t}^{i-j}=\lambda \rho_{m, t-1}^{i-j}+\kappa \mathrm{Z}_{m t}+\eta_{m}+\nu_{m t}^{i-j} .
$$

While this equation is expressed in terms of the low $(i)$ and the middle $(j)$ tiers, we are also interested in estimating analogous specifications for $\rho_{m t}^{i-k}$ and $\rho_{m t}^{j-k}$ as well as for the correlations between each tier and the S\&P 500. To capture the effect of the housing bubble burst, we also include as a regressor the dummy variable $\mathrm{Z}_{m t}$. It changes not only over $t$, but also over $m$ as housing bubbles burst at different times for different metropolitan areas. For a given metropolitan area $m$, the corresponding column in $\mathrm{Z}_{m t}$ is equal to one after the maximum of $P_{m t}^{i}$ is reached and is equal to zero for the dates prior to the maximum.

$\eta_{m}$ captures the metropolitan area time-invariant specific effect while $\nu_{m t}^{i-j}$ is the remaining stochastic term.

In this equation $\lambda$ and $\kappa$ are coefficients to be estimated. Even though the lagged dependent variable is not of direct interest, its inclusion allows us obtain consistent estimates of the effect of the bubble burst on the dynamic correlations because a simple correlation between $\mathrm{Z}_{m t}$ and $\rho_{m t}^{i-j}$ might just be reflecting a common force behind the dynamic adjustment process. Assuming that $\nu_{m t}^{i-j}$ is serially uncorrelated, we model the bubble burst $\mathrm{Z}_{m t}$ as potentially endogenous in the sense that it may be correlated with earlier shocks,

$$
\left.\begin{array}{l}
E\left(\mathrm{Z}_{m s} \nu_{m t}^{i-j}\right)=0, \quad s<t \\
E\left(\mathrm{Z}_{m s} \nu_{m t}^{i-j}\right) \neq 0, \quad s \geq t
\end{array}\right\}, \quad \forall m .
$$

Endogenous $\mathrm{Z}_{m t}$ however does not prevent agents from adopting a forward-looking perspective on the dynamics of either $\rho_{m t}^{i-j}$ or $\mathrm{Z}_{m t}$. The estimation methods we use are consistent 
with rational expectations and only assume that the surprise element of the dynamic correlations $\left(\nu_{m t}^{i-j}\right)$ cannot be predicted.

To obtain consistent estimates of the coefficients $\lambda$ and $\kappa$ we use the methods described in Arellano and Bond (1991) and Blundell and Bond (1998). We first take first differences in Equation (17) to eliminate the metropolitan area time-invariant specific effect $\eta_{m}$ thus obtaining

$$
\Delta \rho_{m t}^{i-j}=\lambda \Delta \rho_{m, t-1}^{i-j}+\kappa \Delta \mathrm{Z}_{m t}+\Delta \nu_{m t}^{i-j}
$$

We then construct the moments $E\left(\Delta \nu_{m t}^{i-j} \mathrm{~W}\right)$ to estimate $\lambda$ and $\kappa$ in Equation (19) via Generalized Method of Moments (GMM). Under the assumption that the error term $\nu_{m t}^{i-j}$ is serially uncorrelated, which we formally test, the lagged values of $\rho_{m, t-1}^{i-j}$ and $\mathrm{Z}_{m t}$ are valid instruments in the matrix $W$. In addition, we use the moments from the equation in levels $E\left[\left(\eta_{m}+\nu_{m t}^{i-j}\right) \mathrm{M}\right]$ where the instruments $\mathrm{M}$ are lags of $\Delta \rho_{m, t-1}^{i-j}$ and $\Delta \mathrm{Z}_{m t}$. These additional moment conditions are needed because, when the series are persistent over time, the instruments $\mathrm{W}$ for the equation in differences might be weak instruments (Blundell and Bond, 1998).

\subsection{Dynamic panel results}

Tables 5 and 6 present pooled OLS and metropolitan area Fixed Effects estimates of the static version of Equation (17). The estimates of the constant presented in column 7 of Table 5 imply than on average the pair-wise correlation between tiers before the bubble burst is about 0.304 . After the bubble burst the point estimate is 0.354 , with the difference of 0.049 being statistically significant at the $1 \%$ level. When considering particular pairwise correlations, in all three cases the correlations are higher after the burst. We interpret this as strong evidence that real hedging has become more attractive after the financial crisis.

[Table 5, about here]

[Table 6, about here]

The point estimates in Table 6 indicate that the correlations between the tiers and the S\&P 500 have increased as well. Column 8 shows that the correlations are 0.032 higher

This article is protected by copyright. All rights reserved. 
after the bubble burst. This is a relatively large increase given that the estimate of the constant in column 7 puts the correlation before the burst at about 0.032 . When comparing the estimates of the constants between Tables 5 and 6 , we observe that before the burst the magnitude of the correlations between different tiers is about ten times larger than the correlations between the S\&P 500 and the tiers. This implies that investing in real estate is a much more effective way to hedge against fluctuations in future home prices than investing in the stock market.

[Table 7, about here]

[Table 8, about here]

The dynamic panel estimates in Tables 7 and 8 are consistent with the static panel results. The main difference is that once we take into account the dynamics and the potential endogeneity of the bubble burst, the magnitude of the difference in the correlations before and after the burst is less than half of the magnitude obtained with the static panels. The difference in magnitude is evidence that the bubble burst can be considered endogenous. Across all columns in Tables 7 and 8 both specification tests validate our choice of estimator. The relatively large p-values associated with the serial correlation test support the assumption of no first order serial correlation. In addition, the relatively large p-values in the Hansen test validate our instruments.

\section{Estimates of the real hedge value of homeownership}

In this section we derive estimates of the real hedge value of homeownership for a typical household depending on its time horizon, time and risk preferences, and the characteristics of the local housing market. For the volatility of the low and the middle tier homes and their correlation we use the estimates for the period after the housing burst reported in Table 9. To estimate the volatility of the renting option specified in equation (9) we use the annualized sample variance of Zillow's quarterly rental index. ${ }^{16}$

[Table 9, about here]

\footnotetext{
${ }^{16}$ We obtained these data from http://www.zillow.com/research/data.
} 
In our parameterization of household preferences we set the coefficient of risk aversion to $\theta=2$, yet our results are amenable to other degrees of risk aversion as the value of the real hedge is proportional to the risk aversion parameter. This flexibility is important as attitudes toward risk are sensitive to demographic characteristics and exhibit variation over time. Furthermore, estimates of risk aversion vary substantially across studies depending on data and method used (surveys, experiments, household portfolio choice observations, or stock market prices). ${ }^{17}$

There is less variation in the literature estimating households' discount factors. Following the macroeconomic and household finance literature (see, e.g. Barberis et al., 2001; Sinai and Souleles, 2005 or Campbell and Cocco, 2015) we set $\delta=0.96$. This value is also consistent with estimates from recent studies using naturally occurring field data, e.g. credit card borrowing data (Laibson et al., 2015). This baseline parameterization is also adaptable to alternative assumptions on the discounting function. ${ }^{18}$

For illustration purposes, let us consider a household with annual income equal to the median annual household income for 2017 which, according to the U.S. Census was $\$ 61,372 .{ }^{19}$ Assuming an effective federal income tax rate of $13.5 \%$, we obtain a median after-tax annual income of $W_{a}=\$ 53,087$ which we use to calculate the volatility of the share of disposable income spent on rent. For the calculation of the risk premium associated with home ownership given by equation (8) we assume a working life of 40 years, i.e. $W=40 \cdot W_{a}$. For these parameter values, we present the value of the real hedge of home

\footnotetext{
${ }^{17}$ Ait-Sahalia and Lo (2000) (see Table V therein) and Bliss and Panigirtzoglou (2000) (see Table VII therein) report estimates of various studies on risk aversion most of which are in the range between 0 and 13, while Guo and Whitelaw (2006) who use stock market data obtain coefficients in the range between 2.5 and 5.6 depending on model specification.

${ }^{18}$ The experimental literature, both in psychology and economics, finds that consumers act impulsively in the sense that they are more sensitive to delays in rewards in the short run than in the long run (Angeletos et al., 2001). This dynamic inconsistency phenomenon is best captured by discount functions for which the discount factor declines over time. We performed calculations using the discounting function suggested by Loewenstein and Prelec (1992). The results are qualitatively similar to our baseline model of exponential discounting. The hyperbolic discounting has the effect of increasing the risk premium of the early rent payments as well as the risk premium of wealth in year $2 T$ associated with the ownership of the middle tier home, and these effects partially offset each other.

${ }^{19}$ See U.S Census release report number CB18-144 dated September 12, 2018 and available at https://www.census.gov/newsroom/press-releases/2018/income-poverty.html.
}

This article is protected by copyright. All rights reserved. 
ownership in San Diego, Denver and Atlanta as a function of the time horizon (see Figure 3). The value of the real hedge depends on the volatility of house appreciation rates relative to the volatility of the percentage change in rent. As can be observed, the real hedge has a positive value in Atlanta and Denver and a negative value in San Diego where house prices relative to rents are more volatile.

Our empirical results suggest that the correlations between tiers is higher in the period after the burst of the housing market bubble. Indeed, the estimates of the conditional correlations reported in Table 9 are higher in the period after the bubble burst across all price tier pairs. The tiered price indices lose value in the immediate aftermath of the bubble burst and recover while moving more closely to each other in the post-crisis period. It can easily be observed that in our theoretical framework an increase in the correlation between the house price tiers increases the value of the real hedge. It reduces the risk premium of home ownership by lowering the variance of the transition between the low and the middle tier home. Indeed, from equations (8), (9) and (10) we obtain

$$
\frac{\partial V(\cdot)}{\partial \rho}=-\frac{\partial \Theta_{O W N}(\cdot)}{\partial \rho}=2 \omega_{i} \omega_{j}\left(\bar{\sigma}_{i, T}\right) \cdot\left(\bar{\sigma}_{j, T}\right)>0
$$

The expression for the partial derivative also illustrates that an increase in the correlation of the appreciation rates between the price tiers increases the value of the real hedge more in high home value markets as well as high volatility markets, i.e. when $\omega_{\tau}$ and $\bar{\sigma}_{\tau, T}$ for $\tau=i, j$ are high.

Note that using the Case-Shiller price indices removes the idiosyncratic element of individual house returns. Yet, it is likely that the correlation of the idiosyncratic elements between tiers is lower than our correlation estimates. Hence, this might bias our correlation estimates and the value of the real hedge upwards. The Case-Shiller tiered price indices are designed to reflect the average change in market prices. Given the low frequency at which houses are transacted, data on the idiosyncratic element of individual house returns is not available. ${ }^{20}$

A further notable implication of our model is that an increase in the correlation coefficient increases the value of the real hedge more in markets with a smaller difference in

\footnotetext{
${ }^{20}$ Rangel and Engle (2012) are able to capture the idiosyncratic element of individual stock returns by employing time series data on all stocks that comprise the Dow Jones Industrial Average (DJIA).
}

This article is protected by copyright. All rights reserved. 
prices between the two tiers. Indeed, let us denote by $\omega=\frac{\frac{P_{i}+P_{j}}{2}}{W}=\frac{\omega_{i}+\omega_{j}}{2}$ the ratio of the average tiered price index to the household's lifetime wealth. We choose the parameter $d \in[0,1)$ so that $(1-d)=\frac{\omega_{i}}{\omega}$ and $(1+d)=\frac{\omega_{j}}{\omega}$. Rearranging the two equations we obtain $d=\frac{\omega_{j}-\omega_{i}}{2 \omega}$, and interpret $d$ as a parameter controlling the difference between the price tiers. With this notation, using equation (20) we obtain

$$
\frac{\partial V(\cdot)}{\partial \rho}=2\left(1-d^{2}\right) \omega^{2}\left(\bar{\sigma}_{i, T}\right) \cdot\left(\bar{\sigma}_{j, T}\right)
$$

which is decreasing in $d$. Further, substituting $\omega_{i}$ and $\omega_{j}$ with $(1-d) \omega$ and $(1+d) \omega$, respectively, in equation (8) we obtain that $\frac{\partial \Theta_{O W N}(\cdot)}{\partial d}<0$ which confirms that the volatility of homeownership is lower when the difference between the two tiers is smaller.

\section{Conclusion}

"Real hedging" is a strategy pursued by households in which a starter home is purchased partly because the household intends to move up the property ladder in the future. In this paper we view real hedging as an investment activity and the choice of home ownership versus renting as a portfolio choice problem. In particular, we represent the two tenure modes as portfolios of hypothetical financial instruments pegged to the home values of each price tier and explore their multiperiod volatilities. Focusing on the insurance aspect of home ownership, we define the value of the real hedge as the difference between the present values of the risk premiums of renting and owning. Our theoretical framework allows us to explore how the value of the real hedge depends on the characteristics of local residential real estate market (correlations between the appreciation rates of price tiers, volatilities of the returns on starter and trade-up homes, house price levels, and momentum, measured by the serial correlation in housing returns) and the characteristics of the household (risk and time preferences, time horizon, and lifetime earnings). The value of the real hedge is directly related to the correlation between the house price tiers. It can be positive when the tiered house prices are strongly correlated and not too volatile relative to rents.

We estimate the dynamic conditional correlations between the Standard \& Poor's CaseShiller tiered price indices for seventeen metropolitan areas over the past 25 years using a DCC-GARCH specification which reflects the structure of our theoretical framework. We 
find positive and statistically significant correlations between price tiers. Furthermore, we pool the time-varying conditional correlations and estimate a dynamic panel specification that takes into account the endogenous nature of the housing crisis. We find an economically and statistically significant increase in the correlation after the crisis which suggests an improvement in the hedging value of home ownership.

\section{References}

Abraham, J. M. and Hendershott, P. H. (1993). Patterns and determinants of metropolitan house prices, 1977 to 1991, pages 18-42. In Browne, Lynn E. and Rosengreen, Eric S. (Ed.) Real Estate and Credit Crunch. Proceedings of the 25th Annual Federal Reserve Bank of Boston Conference. Blackwell: Boston.

Abraham, J. M. and Hendershott, P. H. (1996). Bubbles in metropolitan housing markets. Journal of Housing Research, 7(2):191-207.

Ait-Sahalia, Y. and Lo, A. W. (2000). Nonparametric risk management aind implied risk aversion. Journal of Econometrics, 94(1-2):9-51.

Amior, M. and Halket, J. (2014). Do households use home-ownership to insure themselves? Evidence across U.S. cities. Quantitative Economics, 5(3):631-674.

Angeletos, G.-M., Laibson, D., Repetto, A., Tobachman, J., and Weiberg, S. (2001). International asset allocation with regime shifts. Journal of Economic Perspectives, 15(3):4768.

Arellano, M. and Bond, S. (1991). Some tests of specification for panel data: Monte carlo evidence and an application to employment equations. Review of Economic Studies, $58(2): 277-297$.

Barberis, N., Nuang, M., and Santos, T. (2001). Prospect theory and asset prices. Quarterly Journal of Economics, 116(1):1-53.

Beracha, E. and Skiba, H. (2011). Momentum in residential real estate. Journal of Real Estate Finance and Economics, 43(3):299-320. 
Bliss, R. R. and Panigirtzoglou, N. (2000). Option-implied risk aversion estimates. Journal of Finance, 59(1):407-446.

Blundell, R. and Bond, S. (1998). Initial conditions and moment restrictions in dynamic panel data models. Journal of Econometrics, 87(1):115-143.

Campbell, J. Y. and Cocco, J. F. (2015). A model of mortgage default. Journal of Finance, 70(4):1495-1554.

Capozza, D. R., Hendershott, P. H., and Mack, C. (2004). An anatomy of price dynamics in illiquid markets: Analysis and evidence from local housing markets. Real Estate Economics, 32(1):1-32.

Capozza, D. R. and Seguin, P. J. (1996). Expectations, efficiency, and euphoria in the housing market. Regional Science and Urban Economics, 26(3-4):369-386.

Case, K. E. and Shiller, R. J. (1989). The efficiency of the market for single family homes. Regional Science and Urban Economics, 79(1):125-137.

Case, K. E. and Shiller, R. J. (1990). Forecasting prices and excess returns in the housing market. AREUEA Journal, 18(3):253-273.

Chauvet, M., Gabriel, S., and Lutz, C. (2016). Mortgage default risk: New evidence from internet search queries. Journal of Urban Economics, 96:91-111.

Chiang, T. C., Jeon, B. N., and Li, H. (2007). Dynamic correlation analysis of financial contagion: Evidence from Asian markets. Journal of International Money and Finance, 26(7):1206-1228.

Damianov, D. S. and Escobari, D. (2016). Long-run equilibrium shift and short-run dynamics of U.S. home price tiers during the housing bubble. Journal of Real Estate Finance and Economics, 53(1):1-28.

Davidoff, T. (2006). Labor income, housing prices, and home ownership. Journal of Urban Economics, 59(2):209-235. 
Engle, R. (2002). Dynamic conditional correlation: A simple class of multivariate generalized autoregressive conditional heteroskedasticity models. Journal of Business and Economic Statistics, 20(3):339-350.

Engle, R. F. and Kroner, K. F. (1995). Multivariate simultaneous generalized ARCH. Econometric Theory, 11(1):122-150.

Englund, P., Hwang, M., and Quigley, J. M. (2002). Hedging housing risk. Journal of Real Estate Finance and Economics, 24(1/2):167-200.

Flavin, M. and Nakagawa, S. (2008). A model of housing in the presence of adjustment costs: a structural interpretation of habit persistence. American Economic Review, 98(1):474495.

Flavin, M. and Yamashita, T. (2002). Owner-occupied housing and the composition of the household portfolio. American Economic Review, 92(1):345-362.

Fu, Y. and Ng, L. K. (2001). Market efficiency and return statistics: evidence from real estate and stock markets using a present-value approach. Real Estate Economics, $29(2): 227-250$.

Genesove, D. (2003). The nominal rigidity of apartment rents. Review of Economics and Statistics, 85(4):844-853.

Guo, H. and Whitelaw, R. F. (2006). Uncovering the risk-return relation in the stock market. Journal of Finance, 61(3):1433-1463.

Guren, A. M. (2018). House price momentum and strategic complementarity. Journal of Political Economy, 126(3):1172-1218.

Han, L. (2008). Hedging house price risk in the presence of lumpy transaction costs. Journal of Urban Economics, 64(2):270-287.

Han, L. (2010). The effects of price risk on housing demand: Empirical evidence from U.S. markets. Review of Financial Studies, 23(11):3889-3828.

Hu, X. (2005). Portfolio choice for homeowners. Journal of Urban Economics, 58(1):114136.

This article is protected by copyright. All rights reserved. 
Jegadeesh, N. and Titman, S. (1993). Returns to buying winners and selling losers: Implications for stock market efficiency. Journal of Finance, 48(1):65-91.

Laibson, D., Maxted, P., Repetto, A., and Tobacman, J. (2015). Estimating discount functions with consumer choices over the lifecycle. NBER working paper \# 13314.

Loewenstein, G. and Prelec, D. (1992). Anomalies in intertemporal choice: Evidence and interpretation. Quarterly Journal of Economics, 107(2):573-597.

Lustig, H. N. and Nieuwerburgh, S. G. V. (2005). Housing collateral, consumption insurance, and risk premia: An empirical perspective. Journal of Finance, 60(3):1167-1219.

Miao, H., Ramchander, S., and Simpson, M. W. (2011). Return and volatility transmission in U.S. housing markets. Real Estate Economics, 39(4):701-741.

Ortalo-Magné, F. and Pratt, A. (2016). Spatial asset pricing: A first step. Economica, 83(329):130-171.

Ortalo-Magné, F. and Rady, S. (2002). Tenure choice and the riskiness of non-housing consumption. Journal of Housing Economics, 11(3):266-279.

Piazzesi, M. and Schneider, M. (2009). Momentum traders in the housing market: Survey evidence and a search model. American Economic Review Papers and Proceedings, 99(2):406-411.

Poterba, J. (1991). House price dynamics: the role of tax policy and demography. Brookings Papers on Economic Activity, 2:143-203.

Rangel, J. G. and Engle, R. F. (2012). The Factor-Spline-GARCH model for high and low frequency correlations. Journal of Business and Economic Statistics, 30(1):109-124.

Sinai, T. and Souleles, N. S. (2005). Owner-occupied housing as a hedge against rent risk. Quarterly Journal of Economics, 120(2):763-789.

Sinai, T. and Souleles, N. S. (2013). Can owning a home hedge the risk of moving? American Economic Journal: Economic Policy, 5(2):282-312. 
Stein, J. C. (1995). Prices and trading volume in the housing market: A model of down payment effects. Quarterly Journal of Economics, 110(2):379-406.

This article is protected by copyright. All rights reserved. 


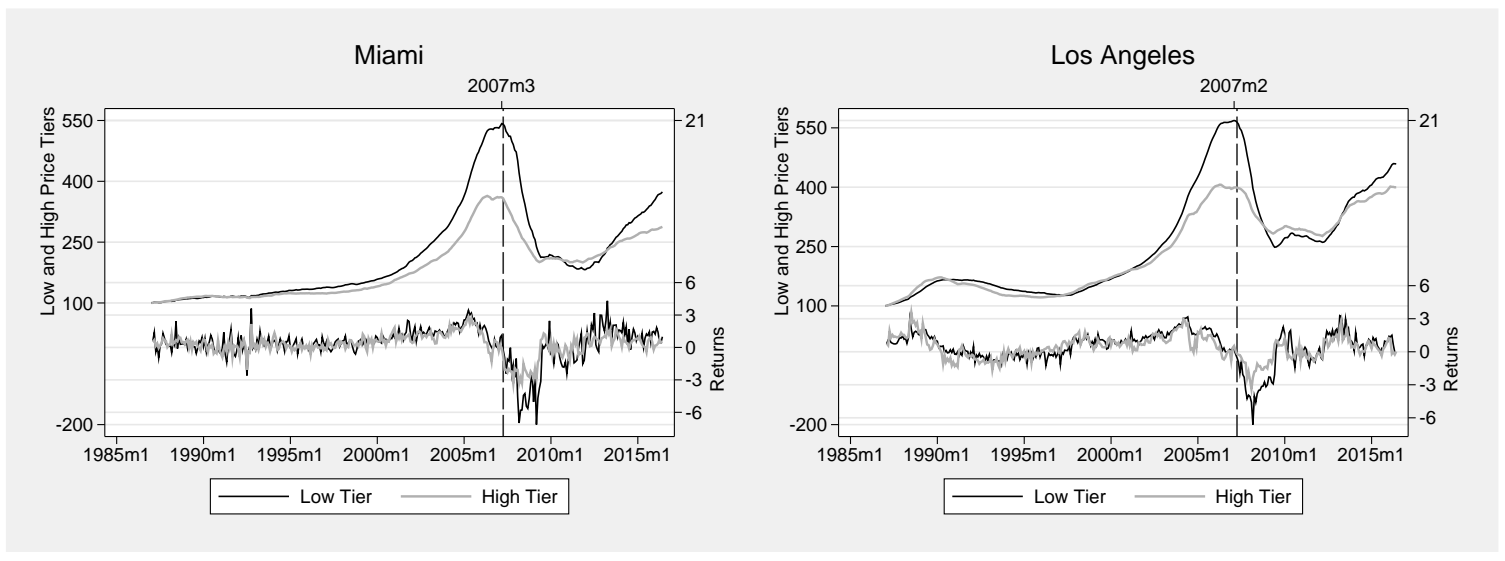

Figure 1: Low and high price tiers and returns for Miami and Los Angeles

This article is protected by copyright. All rights reserved. 

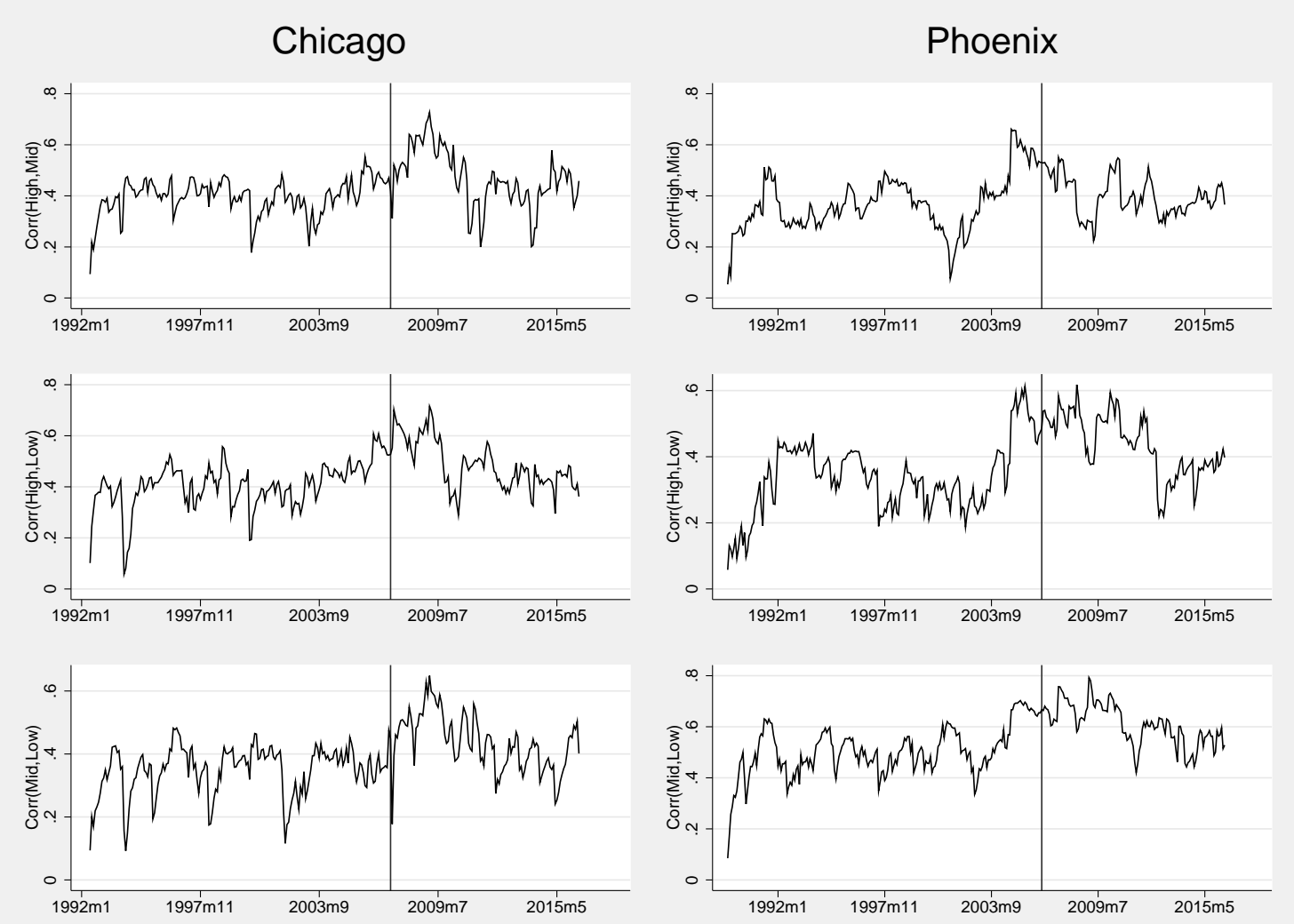

Figure 2: Dynamic correlations for Chicago and Phoenix

This article is protected by copyright. All rights reserved. 


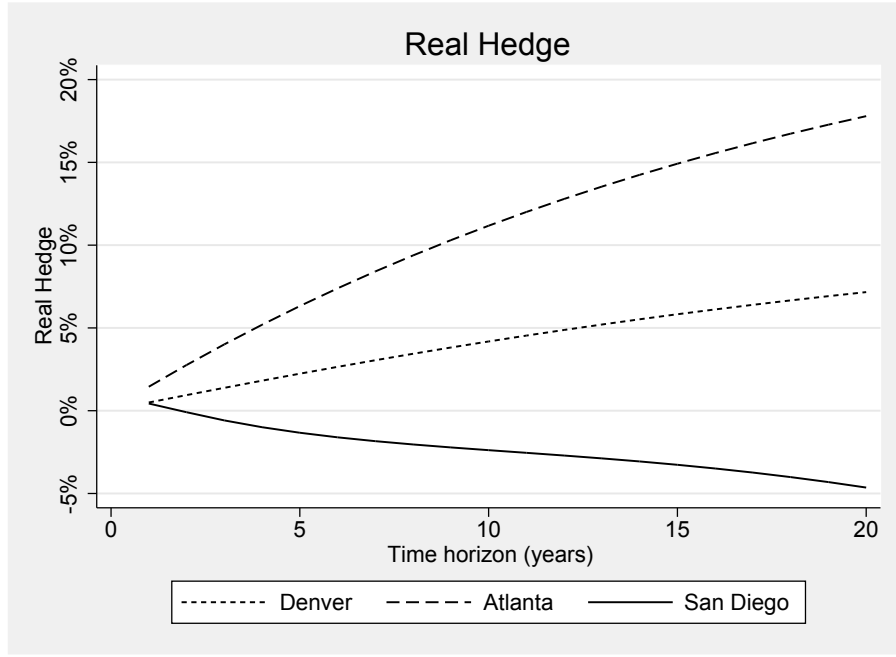

Figure 3: Value of the real hedge for Atlanta, Denver and San Diego. Owning and renting risk premiums are given by equations (8) and (9). The value of the real hedge is given by equation (10). The real hedge is expressed as percentage of the lifetime disposable income of the median U.S. household. Household parameter values are set to $\theta=2.0$, and $\delta=0.96$. Housing market parameters are as reported in Table 9 for the period after the bubble burst.

This article is protected by copyright. All rights reserved. 
Table 1: Mean and standard deviations of the appreciation rates before and after the burst

\begin{tabular}{|c|c|c|c|c|c|c|c|c|c|}
\hline \multirow{3}{*}{ Tiers: } & \multirow[t]{2}{*}{ (1) } & \multirow[t]{2}{*}{$(2)$} & \multirow[t]{2}{*}{$(3)$} & $(4)$ & $(5)$ & (6) & $(7)$ & $(8)$ & (9) \\
\hline & & & & \multicolumn{2}{|c|}{ Low $\left(r_{t}^{i}\right)$} & \multicolumn{2}{|c|}{ Middle $\left(r_{t}^{j}\right)$} & \multicolumn{2}{|c|}{$\operatorname{High}\left(r_{t}^{k}\right)$} \\
\hline & Begin & End & Obs. & Mean & Sd.Dev. & Mean & Sd.Dev. & Mean & Sd.Dev. \\
\hline \multicolumn{10}{|c|}{ Panel A. Before the Bubble Burst: } \\
\hline Atlanta & $1991 \mathrm{~m} 1$ & $2007 \mathrm{~m} 1$ & 193 & 0.401 & 0.401 & 0.330 & 0.263 & 0.339 & 0.313 \\
\hline Boston & $1987 \mathrm{~m} 1$ & $2006 \mathrm{~m} 1$ & 229 & 0.510 & 0.893 & 0.416 & 0.665 & 0.379 & 0.625 \\
\hline Chicago & $1992 \mathrm{~m} 1$ & $2007 \mathrm{~m} 3$ & 183 & 0.557 & 0.646 & 0.474 & 0.393 & 0.427 & 0.434 \\
\hline Cleveland & $1987 \mathrm{~m} 1$ & $2005 \mathrm{~m} 5$ & 221 & 0.505 & 0.854 & 0.385 & 0.407 & 0.328 & 0.422 \\
\hline Denver & $1987 \mathrm{~m} 1$ & $2005 \mathrm{~m} 4$ & 220 & 0.526 & 0.786 & 0.453 & 0.556 & 0.420 & 0.493 \\
\hline Las Vegas & $1993 \mathrm{~m} 1$ & $2006 \mathrm{~m} 7$ & 163 & 0.723 & 1 & 0.621 & 1.083 & 0.611 & 1.036 \\
\hline Los Angeles & $1987 \mathrm{~m} 1$ & $2007 \mathrm{~m} 2$ & 242 & 0.721 & 0.965 & 0.642 & 0.953 & 0.574 & 0.974 \\
\hline Miami & $1987 \mathrm{~m} 1$ & $2007 \mathrm{~m} 3$ & 243 & 0.699 & 0.876 & 0.608 & 0.736 & 0.530 & 0.718 \\
\hline Minneapolis & $1989 \mathrm{~m} 1$ & $2006 \mathrm{~m} 4$ & 208 & 0.587 & 0.630 & 0.497 & 0.466 & 0.429 & 0.526 \\
\hline New York & $1987 \mathrm{~m} 1$ & $2007 \mathrm{~m} 3$ & 243 & 0.536 & 0.809 & 0.440 & 0.652 & 0.390 & 0.591 \\
\hline Phoenix & $1989 \mathrm{~m} 1$ & $2006 \mathrm{~m} 6$ & 210 & 0.640 & 0.891 & 0.565 & 0.851 & 0.566 & 0.791 \\
\hline Portland & $1987 \mathrm{~m} 1$ & $2007 \mathrm{~m} 5$ & 245 & 0.777 & 0.835 & 0.639 & 0.603 & 0.549 & 0.629 \\
\hline San Diego & $1989 \mathrm{~m} 1$ & $2006 \mathrm{~m} 4$ & 208 & 0.719 & 0.945 & 0.611 & 0.885 & 0.547 & 0.892 \\
\hline San Francisco & $1987 \mathrm{~m} 1$ & $2006 \mathrm{~m} 5$ & 233 & 0.751 & 0.908 & 0.670 & 0.921 & 0.600 & 0.964 \\
\hline Seattle & 1990m1 & $2007 \mathrm{~m} 5$ & 209 & 0.705 & 0.618 & 0.583 & 0.640 & 0.516 & 0.792 \\
\hline Tampa & $1987 \mathrm{~m} 1$ & $2006 \mathrm{~m} 7$ & 235 & 0.628 & 0.990 & 0.503 & 0.669 & 0.428 & 0.744 \\
\hline Washington DC & $1987 \mathrm{~m} 1$ & $2007 \mathrm{~m} 3$ & 243 & 0.632 & 0.818 & 0.551 & 0.726 & 0.499 & 0.747 \\
\hline \multicolumn{10}{|c|}{ Panel B. After the Bubble Burst: } \\
\hline Atlanta & $2007 \mathrm{~m} 2$ & $2016 \mathrm{~m} 6$ & 113 & -0.150 & 3.036 & -0.0471 & 1.442 & -0.00874 & 0.901 \\
\hline Boston & $2006 \mathrm{~m} 2$ & $2016 \mathrm{~m} 6$ & 125 & 0.0120 & 1.338 & 0.0300 & 0.828 & 0.0474 & 0.629 \\
\hline Chicago & $2007 \mathrm{~m} 4$ & $2016 \mathrm{~m} 6$ & 111 & -0.276 & 1.916 & -0.224 & 1.071 & -0.177 & 0.904 \\
\hline Cleveland & $2005 \mathrm{~m} 6$ & $2008 \mathrm{~m} 11$ & 42 & -1.106 & 3.980 & -0.315 & 0.788 & -0.234 & 0.895 \\
\hline Denver & $2005 \mathrm{~m} 5$ & $2016 \mathrm{~m} 6$ & 134 & 0.298 & 1.054 & 0.270 & 0.656 & 0.178 & 0.569 \\
\hline Las Vegas & $2006 \mathrm{~m} 8$ & $2016 \mathrm{~m} 6$ & 119 & -0.372 & 2.454 & -0.375 & 1.762 & -0.357 & 1.493 \\
\hline Los Angeles & $2007 \mathrm{~m} 3$ & $2016 \mathrm{~m} 6$ & 112 & -0.191 & 1.943 & -0.0918 & 1.352 & 0.00170 & 1.040 \\
\hline Miami & $2007 \mathrm{~m} 4$ & $2016 \mathrm{~m} 6$ & 111 & -0.335 & 2.332 & -0.250 & 1.594 & -0.204 & 1.300 \\
\hline Minneapolis & $2006 \mathrm{~m} 5$ & $2016 \mathrm{~m} 6$ & 122 & -0.121 & 2.443 & -0.0733 & 1.372 & -0.113 & 1.039 \\
\hline New York & $2007 \mathrm{~m} 4$ & $2016 \mathrm{~m} 6$ & 111 & -0.239 & 0.875 & -0.157 & 0.699 & -0.0841 & 0.534 \\
\hline Phoenix & $2006 \mathrm{~m} 7$ & $2016 \mathrm{~m} 6$ & 120 & -0.311 & 3.069 & -0.269 & 1.731 & -0.284 & 1.317 \\
\hline Portland & $2007 \mathrm{~m} 6$ & $2016 \mathrm{~m} 6$ & 109 & 0.148 & 1.286 & 0.120 & 1.032 & 0.0369 & 0.928 \\
\hline San Diego & $2006 \mathrm{~m} 5$ & $2016 \mathrm{~m} 6$ & 122 & -0.109 & 1.640 & -0.0968 & 1.213 & -0.0684 & 1.111 \\
\hline San Francisco & $2006 \mathrm{~m} 6$ & $2016 \mathrm{~m} 6$ & 121 & -0.132 & 2.235 & 0.0201 & 1.495 & 0.146 & 1.223 \\
\hline Seattle & $2007 \mathrm{~m} 6$ & $2016 \mathrm{~m} 6$ & 109 & -0.0419 & 1.267 & 0.0238 & 1.008 & 0.0712 & 0.914 \\
\hline Tampa & $2006 \mathrm{~m} 8$ & $2016 \mathrm{~m} 6$ & 119 & -0.281 & 2.155 & -0.244 & 1.314 & -0.183 & 1.117 \\
\hline Washington DC & $2007 \mathrm{~m} 4$ & $2016 \mathrm{~m} 6$ & 111 & -0.226 & 1.725 & -0.131 & 1.055 & -0.0382 & 0.669 \\
\hline
\end{tabular}

Notes: Total number of observations is 4,229. The monthly appreciation rates, reported in percentage terms are calculated as $r_{t}^{\tau}=\left(p_{t}^{\tau}-p_{t-1}^{\tau}\right) \cdot 100=\left[\log \left(P_{t}^{\tau}\right)-\log \left(P_{t-1}^{\tau}\right)\right] \cdot 100$ for $\tau=i, j, k . P_{t}^{\tau}$ is the S\&P Case-Shiller price tier for the corresponding metropolitan market.

This article is protected by copyright. All rights reserved. 
Table 2: Unconditional correlations before and after the burst

\begin{tabular}{|c|c|c|c|c|c|c|c|c|}
\hline \multirow{3}{*}{ Correlation: } & (1) & $(2)$ & (3) & (4) & $(5)$ & (6) & (7) & (8) \\
\hline & \multicolumn{4}{|c|}{$\rho^{k-\mathrm{S} \& \mathrm{P}}$} & \multicolumn{4}{|c|}{$\rho^{i-k}$} \\
\hline & Before & After & z-stat & p-value & Before & After & z-stat & p-value \\
\hline \multicolumn{9}{|c|}{ Metropolitan Statistical Area: } \\
\hline Atlanta & -0.0268 & 0.236 & -2.227 & 0.013 & 0.217 & 0.631 & -4.349 & 0.000 \\
\hline Boston & -0.150 & 0.178 & -2.944 & 0.002 & 0.605 & 0.330 & 3.178 & 0.999 \\
\hline Chicago & -0.0323 & 0.290 & -2.713 & 0.003 & 0.306 & 0.616 & -3.309 & 0.000 \\
\hline Cleveland & -0.139 & 0.218 & -2.079 & 0.019 & 0.102 & -0.0921 & 1.121 & 0.869 \\
\hline Denver & -0.0112 & 0.374 & -3.647 & 0.000 & 0.481 & 0.536 & -0.669 & 0.252 \\
\hline Las Vegas & -0.0215 & 0.225 & -2.052 & 0.020 & 0.765 & 0.824 & -1.321 & 0.093 \\
\hline Los Angeles & -0.0589 & 0.268 & -2.884 & 0.002 & 0.805 & 0.880 & -2.273 & 0.012 \\
\hline Miami & -0.150 & 0.273 & -3.717 & 0.000 & 0.764 & 0.787 & -0.497 & 0.309 \\
\hline Minneapolis & -0.0121 & 0.192 & -1.786 & 0.037 & 0.384 & 0.676 & -3.613 & 0.000 \\
\hline New York & -0.0746 & 0.0793 & -1.330 & 0.092 & 0.686 & 0.532 & 2.136 & 0.984 \\
\hline Phoenix & -0.0120 & 0.336 & -3.125 & 0.001 & 0.812 & 0.869 & -1.692 & 0.045 \\
\hline Portland & -0.00270 & 0.0789 & -0.702 & 0.241 & 0.253 & 0.703 & -5.281 & 0.000 \\
\hline San Diego & -0.0378 & 0.245 & -2.494 & 0.006 & 0.764 & 0.773 & -0.196 & 0.422 \\
\hline San Francisco & -0.0686 & 0.252 & -2.880 & 0.002 & 0.697 & 0.725 & -0.504 & 0.307 \\
\hline Seattle & 0.0741 & 0.139 & -0.546 & 0.293 & 0.466 & 0.719 & -3.351 & 0.000 \\
\hline Tampa & -0.0259 & 0.311 & -3.054 & 0.001 & 0.454 & 0.592 & -1.679 & 0.047 \\
\hline Washington DC & -0.129 & 0.261 & -3.426 & 0.000 & 0.660 & 0.549 & 1.524 & 0.936 \\
\hline
\end{tabular}

Notes: Total number of observations is 4,229 . The null hypothesis is that the correlations are the same, and the alternative is that the correlation is smaller before the bubble burst.

This article is protected by copyright. All rights reserved. 


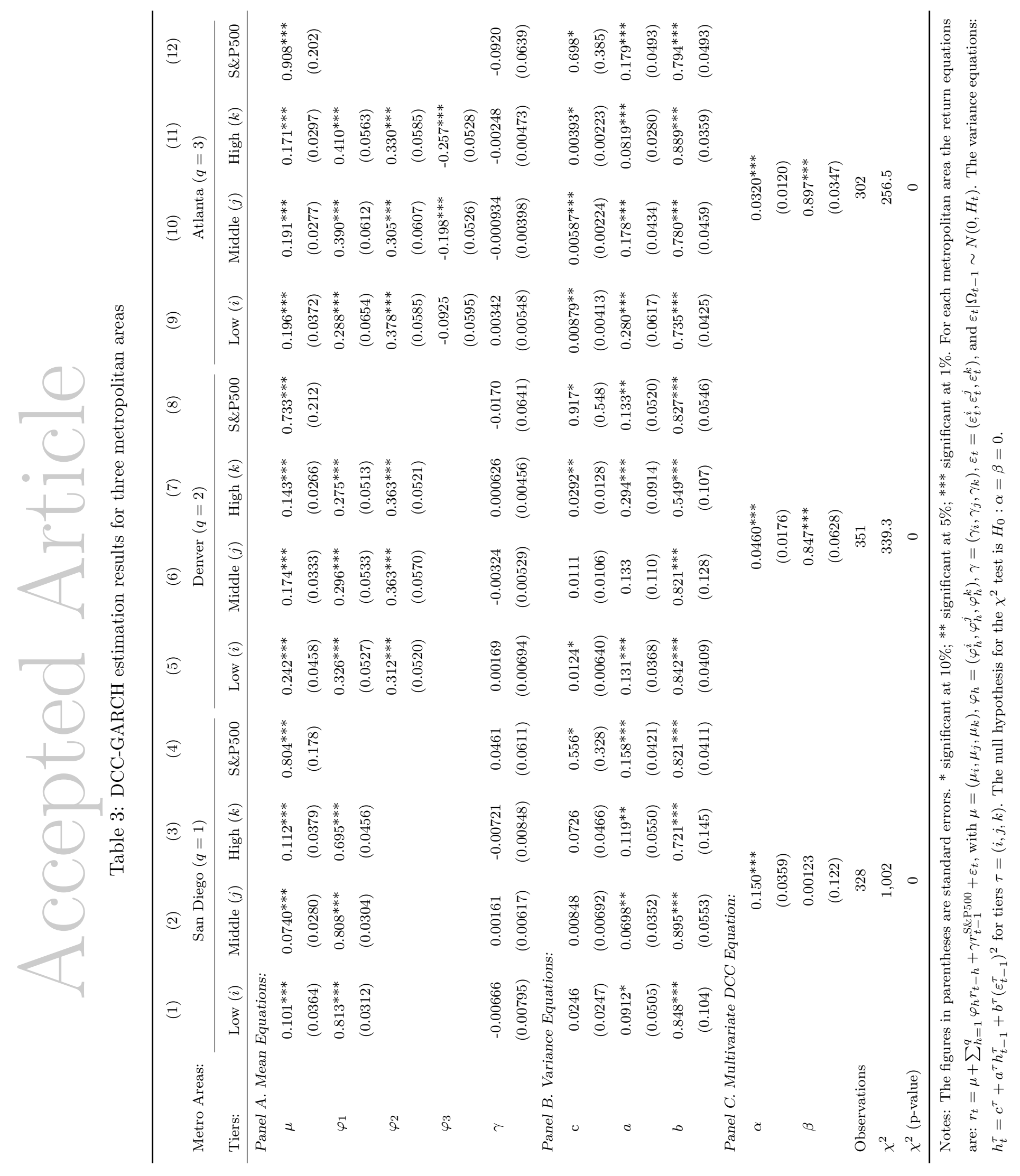




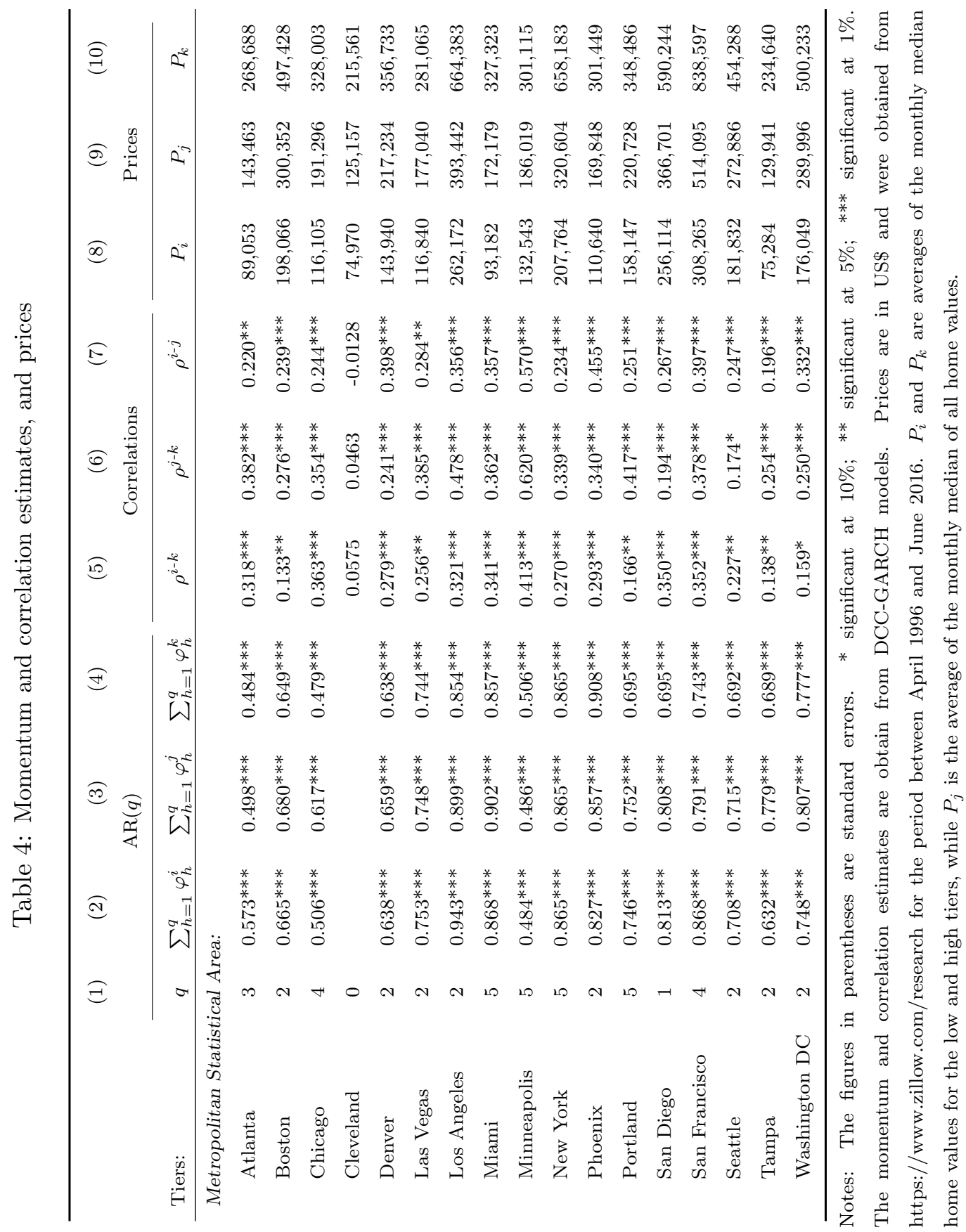

This article is protected by copyright. All rights reserved. 
Table 5: Panel data results. Correlations within tiers

\begin{tabular}{|c|c|c|c|c|c|c|c|c|}
\hline \multirow{3}{*}{$\begin{array}{l}\text { Dep. Variable: } \\
\text { Estimator: }\end{array}$} & (1) & $(2)$ & (3) & $(4)$ & $(5)$ & (6) & (7) & (8) \\
\hline & \multicolumn{2}{|c|}{ Low-High $\left(\rho_{m t}^{i-k}\right)$} & \multicolumn{2}{|c|}{ Middle-High $\left(\rho_{m t}^{j-k}\right)$} & \multicolumn{2}{|c|}{ Low-Middle $\left(\rho_{m t}^{i-j}\right)$} & \multicolumn{2}{|c|}{ All } \\
\hline & Pooled & $\mathrm{FE}$ & Pooled & $\mathrm{FE}$ & Pooled & FE & Pooled & $\mathrm{FE}$ \\
\hline \multicolumn{9}{|l|}{ Variables: } \\
\hline Bubble Burst & $\begin{array}{c}0.0512^{* * *} \\
(0.00291)\end{array}$ & $\begin{array}{c}0.0411^{* * *} \\
(0.00193)\end{array}$ & $\begin{array}{c}0.0411^{* * *} \\
(0.00303)\end{array}$ & $\begin{array}{c}0.0359 * * * \\
(0.00198)\end{array}$ & $\begin{array}{c}0.0566^{* * *} \\
(0.00318)\end{array}$ & $\begin{array}{c}0.0477^{* * *} \\
(0.00200)\end{array}$ & $\begin{array}{c}0.0496^{* * *} \\
(0.00178)\end{array}$ & $\begin{array}{c}0.0415^{* * *} \\
(0.00130)\end{array}$ \\
\hline Constant & $\begin{array}{c}0.270^{* * *} \\
(0.00171)\end{array}$ & & $\begin{array}{l}0.329^{* * *} \\
(0.00178)\end{array}$ & & $\begin{array}{l}0.312^{* * *} \\
(0.00187)\end{array}$ & & $\begin{array}{c}0.304^{* * *} \\
(0.00105)\end{array}$ & \\
\hline Observations & 11,146 & 11,146 & 11,146 & 11,146 & 11,146 & 11,146 & 33,438 & 33,438 \\
\hline R-squared & 0.027 & 0.912 & 0.016 & 0.931 & 0.028 & 0.927 & 0.023 & 0.901 \\
\hline
\end{tabular}

Notes: The figures in parentheses are standard errors. ${ }^{*}$ significant at $10 \%$; ${ }^{* *}$ significant at $5 \%$; ${ }^{* * *}$ significant at $1 \%$.

Table 6: Panel data results. Correlations between the tiers and the S\&P 500

\begin{tabular}{|c|c|c|c|c|c|c|c|c|}
\hline \multirow{3}{*}{$\begin{array}{l}\text { Dep. Variable: } \\
\text { Estimator: }\end{array}$} & (1) & $(2)$ & (3) & (4) & (5) & $(6)$ & $(7)$ & (8) \\
\hline & \multicolumn{2}{|c|}{ Low-High $\left(\rho_{m t}^{i-k}\right)$} & \multicolumn{2}{|c|}{ Middle-High $\left(\rho_{m t}^{j-k}\right)$} & \multicolumn{2}{|c|}{ Low-Middle $\left(\rho_{m t}^{i-j}\right)$} & \multicolumn{2}{|c|}{ All } \\
\hline & Pooled & $\mathrm{FE}$ & Pooled & $\mathrm{FE}$ & Pooled & $\mathrm{FE}$ & Pooled & $\mathrm{FE}$ \\
\hline \multicolumn{9}{|l|}{ Variables: } \\
\hline \multirow[t]{2}{*}{ Bubble Burst } & $0.0325 * * *$ & $0.0314^{* * *}$ & $0.0260 * * *$ & $0.0243^{* * *}$ & $0.0468^{* * *}$ & $0.0392^{* * *}$ & $0.0351 * * *$ & $0.0316^{* * *}$ \\
\hline & $(0.00261)$ & $(0.00236)$ & $(0.00294)$ & $(0.00238)$ & $(0.00275)$ & $(0.00237)$ & $(0.00160)$ & $(0.00144)$ \\
\hline \multirow[t]{2}{*}{ Constant } & $0.0331^{* * *}$ & & $0.0290^{* * *}$ & & $0.0337 * * *$ & & $0.0319 * * *$ & \\
\hline & $(0.00153)$ & & $(0.00173)$ & & $(0.00162)$ & & $(0.000941)$ & \\
\hline Observations & 5,573 & 5,573 & 5,573 & 5,573 & 5,573 & 5,573 & 16,719 & 16,719 \\
\hline R-squared & 0.027 & 0.359 & 0.014 & 0.436 & 0.050 & 0.443 & 0.028 & 0.352 \\
\hline
\end{tabular}

Notes: The figures in parentheses are standard errors. ${ }^{*}$ significant at $10 \% ;{ }^{* *}$ significant at $5 \%$; ${ }^{* *}$ significant at $1 \%$.

This article is protected by copyright. All rights reserved. 
Table 7: Dynamic panel data results. Correlations within tiers

\begin{tabular}{lcccc}
\hline & $(1)$ & $(2)$ & $(3)$ & $(4)$ \\
Dep. Variable: & Low-High $\left(\rho_{m t}^{i-k}\right)$ & Middle-High $\left(\rho_{m t}^{j-k}\right)$ & Low-Middle $\left(\rho_{m t}^{i-j}\right)$ & All \\
\hline & & & & \\
Lagged Dep. Variable & $0.733^{* * *}$ & $0.710^{* * *}$ & $0.727^{* * *}$ & $0.719^{* * *}$ \\
& $(0.0126)$ & $(0.00767)$ & $(0.00961)$ & $(0.00379)$ \\
Bubble Burst & $0.0163^{* * *}$ & $0.0127^{* * *}$ & $0.0155^{* * *}$ & $0.0133^{* * *}$ \\
& $(0.000862)$ & $(0.00189)$ & $(0.00117)$ & $(0.000433)$ \\
& & & & 33,336 \\
Observations & 11,112 & 11,112 & 11,112 & 96 \\
Instruments & 32 & 32 & 1.401 & 1.614 \\
Serial Correlation & -1.318 & 1.082 & 0.161 & 0.107 \\
Serial Correlation (p-value) & 0.187 & 0.279 & 28.42 & 100.4 \\
Hansen & 25.01 & 30.07 & 0.496 & 0.283 \\
Hansen (p-value) & 0.678 & 1 & 32 & \\
\hline
\end{tabular}

Notes: Figures in parentheses are the Windmeijer finite-sample corrected standard errors of the GMM twostep estimates. ${ }^{*}$ significant at $10 \%$; ${ }^{* *}$ significant at $5 \%$; ${ }^{* *}$ significant at $1 \%$. ${ }^{a}$ The null hypothesis is that the errors in the first-difference regression exhibit no second-order serial correlation (valid specification). ${ }^{b}$ The null hypothesis is that the instruments are not correlated with the residuals (valid specification).

Table 8: Dynamic panel data results. Correlations between the tiers and the S\&P 500

\begin{tabular}{lcccc}
\hline & $(1)$ & $(2)$ & $(3)$ & $(4)$ \\
Dep. Variable: & Low-High $\left(\rho_{m t}^{i-k}\right)$ & Middle-High $\left(\rho_{m t}^{j-k}\right)$ & Low-Middle $\left(\rho_{m t}^{i-j}\right)$ & All \\
\hline Lagged Dep. Variable & $0.697^{* * *}$ & $0.709^{* * *}$ & $0.704^{* * *}$ & $0.710^{* * *}$ \\
& $(0.0179)$ & $(0.00793)$ & $(0.00756)$ & $(0.00359)$ \\
Bubble Burst & $0.00875^{* * *}$ & $0.00700^{* * *}$ & $0.0141^{* * *}$ & $0.00948^{* * *}$ \\
& $(0.00102)$ & $(0.000611)$ & $(0.000868)$ & $(0.000224)$ \\
Observations & & & & 16,668 \\
Instruments & 5,556 & 5,556 & 5,556 & 48 \\
Serial Correlation & 16 & 16 & 16 & 0.777 \\
Serial Correlation (p-value) & 0.0877 & 1.353 & -0.513 & 0.437 \\
Hansen & 15.81 & 0.176 & 0.608 & 50.27 \\
Hansen (p-value) & 0.260 & 13.45 & 12.76 & 0.273 \\
\hline
\end{tabular}

Notes: Figures in parentheses are the Windmeijer finite-sample corrected standard errors of the GMM twostep estimates. ${ }^{*}$ significant at $10 \%$; ${ }^{* *}$ significant at $5 \%$; ${ }^{* *}$ significant at $1 \%$. ${ }^{a}$ The null hypothesis is that the errors in the first-difference regression exhibit no second-order serial correlation (valid specification). ${ }^{b}$ The null hypothesis is that the instruments are not correlated with the residuals (valid specification).

This article is protected by copyright. All rights reserved. 
Table 9: Volatility and correlation estimates before and after the bubble burst

\begin{tabular}{|c|c|c|c|c|c|c|}
\hline \multirow[b]{3}{*}{ Tiers } & $(1)$ & $(2)$ & (3) & $(4)$ & $(5)$ & $(6)$ \\
\hline & \multicolumn{3}{|c|}{ Volatilities } & \multicolumn{3}{|c|}{ Correlations } \\
\hline & Low $\left(\hat{\sigma}_{i}\right)$ & Middle $\left(\hat{\sigma_{j}}\right)$ & $\operatorname{High}\left(\hat{\sigma_{k}}\right)$ & Low-High $\left(\hat{\rho}^{i-k}\right)$ & Middle-High $\left(\hat{\rho}^{j-k}\right)$ & Low-Middle $\left(\hat{\rho}^{i-j}\right)$ \\
\hline Before & 0.661 & 0.451 & 0.507 & 0.287 & 0.361 & 0.332 \\
\hline After & 1.243 & 0.713 & 0.644 & 0.356 & 0.415 & 0.401 \\
\hline
\end{tabular}

Notes: Figures represent estimates of conditional volatilities and correlations. Estimates are obtained by estimating the parameters for each individual metropolitan area and taking averages across all areas for the periods before and after the housing bubble burst.

This article is protected by copyright. All rights reserved. 